Portland State University

PDXScholar

\title{
Factors Affecting Behavioral Changes in Response to Road Fees: Some Analyses of the Effect of Attitudes, Transit Access, and Fuel Efficiency on Changes in Miles Driven
}

Anthony M. Rufolo

Portland State University

Follow this and additional works at: https://pdxscholar.library.pdx.edu/trec_reports

Part of the Transportation Commons, Urban Studies Commons, and the Urban Studies and Planning Commons

Let us know how access to this document benefits you.

\section{Recommended Citation}

Rufolo, Anthony M.. Factors Affecting Behavioral Changes in Response to Road Fees: Some Analyses of the Effect of Attitudes, Transit Access, and Fuel Efficiency on Changes in Miles Driven. OTREC-RR-09-01. Portland, OR: Transportation Research and Education Center (TREC), 2009. https://doi.org/10.15760/ trec.72

This Report is brought to you for free and open access. It has been accepted for inclusion in TREC Final Reports by an authorized administrator of PDXScholar. Please contact us if we can make this document more accessible: pdxscholar@pdx.edu. 


\section{S)OTREC}

FINAL REPORT

\section{Factors Affecting Behavioral Changes in Response to Road Fees:} Some Analyses of the Effect of Attitudes, Transit Access, and Fuel Efficiency on Changes in Miles Driven

OTREC-RR-09-01 February 2009 



\title{
FACTORS AFFECTING BEHAVIORAL CHANGES IN RESPONSE TO ROAD FEES: SOME ANALYSES OF THE EFFECT OF ATTITUDES, TRANSIT ACCESS, AND FUEL EFFICIENCY ON CHANGES IN MILES DRIVEN
}

\author{
Final Report \\ OTREC-RR-09-01 \\ by \\ Anthony M. Rufolo \\ Portland State University
}

for

Oregon Transportation Research and Education Consortium (OTREC)

P.O. Box 751

Portland, OR 97207

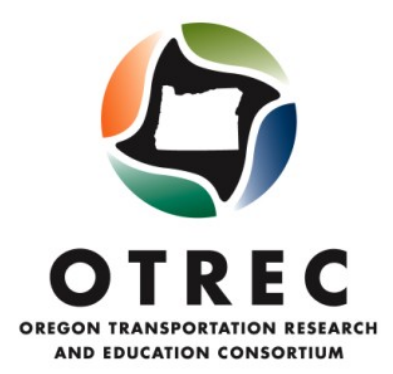

February 2009 



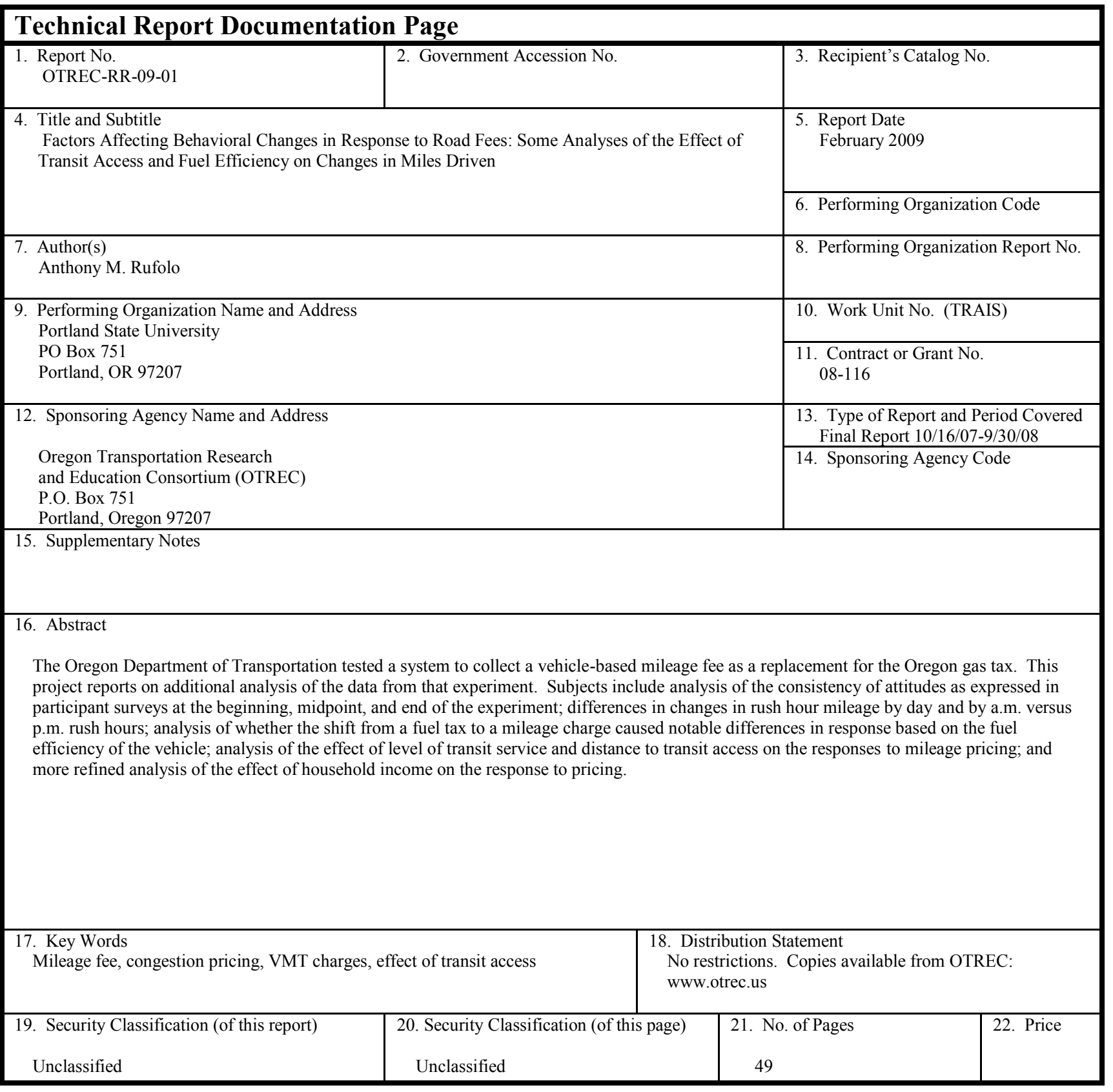




\section{ACKNOWLEDGEMENTS}

This project was funded by the Oregon Transportation Research and Education Consortium (OTREC).

\section{DISCLAIMER}

The contents of this report reflect the views of the authors, who are solely responsible for the facts and the accuracy of the material and information presented herein. This document is disseminated under the sponsorship of the U.S. Department of Transportation University Transportation Centers Program and Portland State University in the interest of information exchange. The U.S. Government and Portland State University assume no liability for the contents or use thereof. The contents do not necessarily reflect the official views of the U.S. Government or Portland State University. This report does not constitute a standard, specification, or regulation. 


\section{TABLE OF CONTENTS}

EXECUTIVE SUMMARY ................................................................................................ VII

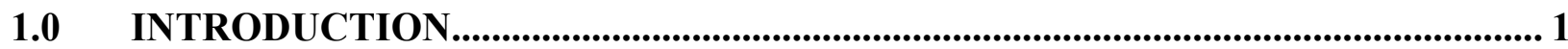

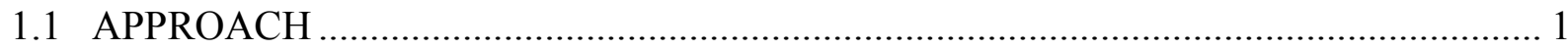

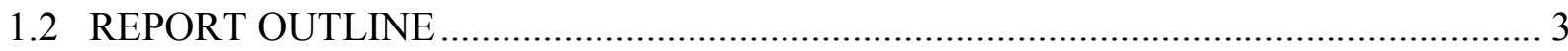

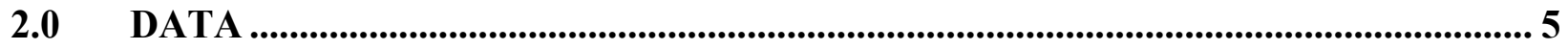

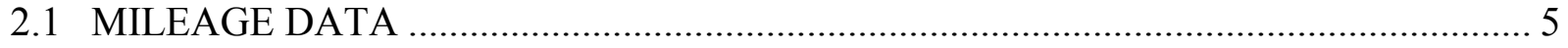

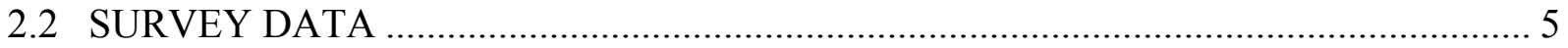

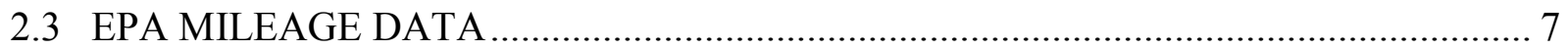

3.0 ATTITUDES EXPRESSED IN THE SURVEYS .......................................................... 9

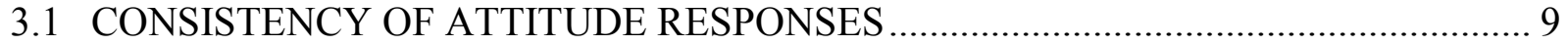

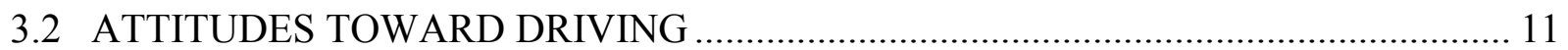

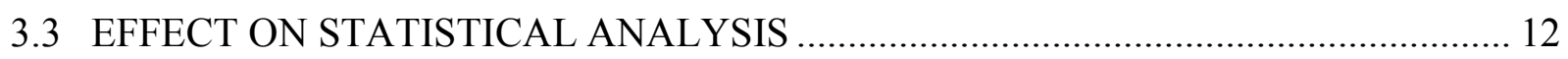

4.0 PRICING AND VEHICLE MPG........................................................................ 17

5.0 VARIATIONS IN RUSH HOUR MILEAGE CHANGES ......................................... 19

6.0 EFFECT OF TRANSIT SERVICE ON MILEAGE CHANGES................................. 21

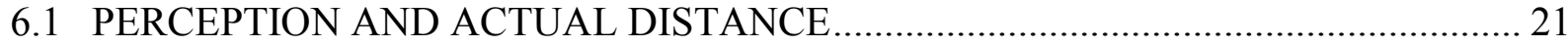

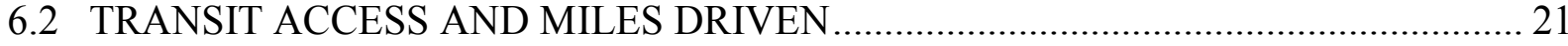

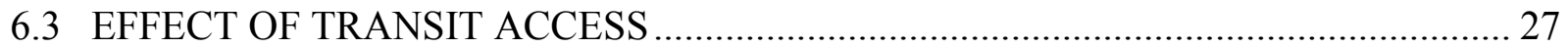

7.0 EFFECT OF HOUSEHOLD INCOME ON MILEAGE AND CHANGES IN

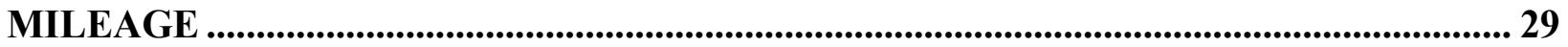

8.0 COMPARISON WITH OTHER EXPERIMENTS...................................................... 33

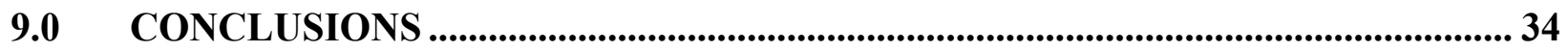

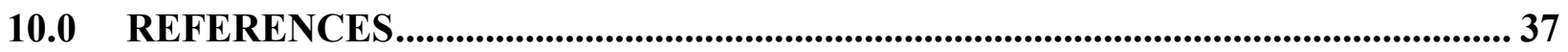

\section{LIST OF TABLES}

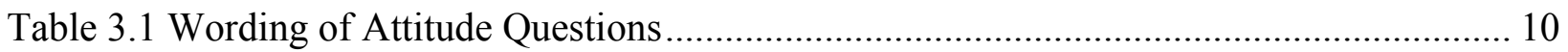

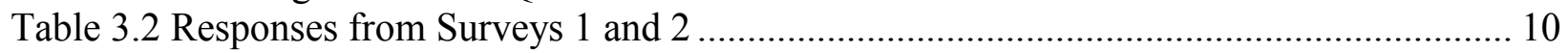

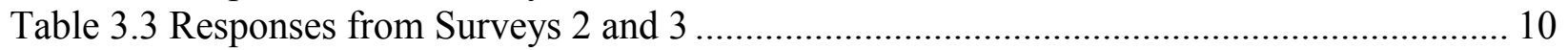

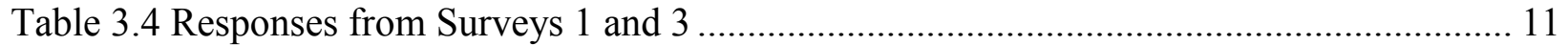

Table 3.5 Response Patterns ............................................................................................... 12

Table 3.6 Baseline Period- Rush Hour Miles per Vehicle per Weekday, Total Oregon Miles per

Vehicle per Day, and Total Miles per Vehicle per Day- Survey 2 ………………………..... 13

Table 3.7 Baseline Period- Rush Hour Miles per Vehicle per Weekday, Total Oregon Miles per

Vehicle per Day, and Total Miles per Vehicle per Day- Survey 3 ...................................... 13

Table 3.8 Change in Rush Hour Miles per Vehicle per Weekday, Change in Total Oregon Miles

per Vehicle per Day, and Change in Total Miles per Vehicle per Day- Survey 2................ 15 
Table 3.9 Change in Rush Hour Miles per Vehicle per Weekday, Change in Total Oregon Miles per Vehicle per Day, and Change in Total Miles per Vehicle per Day- Survey 3................ 16

Table 4.1 Baseline Period- Rush Hour Miles per Vehicle per Weekday, Total Oregon Miles per

Vehicle per Day, and Total Miles per Vehicle per Day With EPA Estimates....................... 17

Table 5.1 Changes In Total Rush Hour Miles by A.M. and P.M. (Weekday)............................... 19

Table 5.2 Changes In A.M. Rush Hour Miles By Weekday ....................................................... 20

Table 5.3 Changes In P.M. Rush Hour Miles By Weekday ........................................................ 20

Table 6.1 Descriptive Statistics for the Full Sample- Self-Reported Transit Access .................... 22

Table 6.2 Baseline Period Regressions- Rush Hour Miles Per Vehicle per Weekday and Total

Miles per Vehicle per Day Self-Reported Transit Access ..................................................... 23

Table 6.3 Change Regressions- Rush Hour Miles per Vehicle Per Weekday and Total Miles per

Vehicle Per Day Self-Reported Transit Access .................................................................... 23

Table 6.4 Descriptive Statistics for the Full Sample- GIS-Based Transit Access ........................ 25

Table 6.5 Baseline Period Effect of Distance to Transit on Miles Driven .................................. 25

Table 6.6 Effect of Distance to Transit on Changes in Miles ...................................................... 26

Table 7.1 Baseline Period- Effect of Income On Rush Hour Miles per Vehicle per Weekday,

Total Oregon Miles per Vehicle per Day, and Total Miles per Vehicle per Day .................. 29

Table 7.2 Effect of Income On Change in Rush Hour Miles per Vehicle per Weekday, Change in

Total Oregon Miles per Vehicle per Day, and Change in Total Miles per Vehicle per Day 30

\section{LIST OF FIGURES}

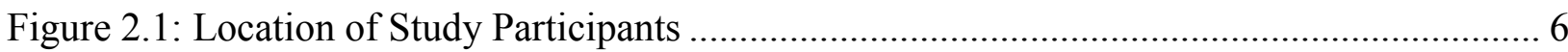




\section{EXECUTIVE SUMMARY}

The Oregon Department of Transportation (ODOT) tested a system to collect a vehicle-based mileage fee as a replacement for the Oregon gas tax. This project reports on additional analysis of the data from that experiment. Subjects include analysis of the consistency of attitudes as expressed in participant surveys at the beginning, midpoint, and end of the experiment; differences in changes in rush hour mileage by day of the week and by a.m. versus p.m. rush hours; analysis of whether the shift from a fuel tax to a mileage charge caused notable differences in response based on vehicle fuel efficiency; analysis of the effect of transit service availability and distance to transit access on the responses to mileage pricing; and more refined analysis of the effect of household income on the response to pricing.

The initial analysis of the survey data from the experiment revealed that there were large and inconsistent changes in a key attitude question from survey to survey. It was hypothesized that this might be due to some people responding based on what they thought the experiment was designed to do. The changes in survey responses were examined for a variety of the attitude questions, and there was substantial consistency in the responses to most questions. However, the responses to the statement "Offered a choice between convenient public transportation and taking a car, I would always drive a car, even in rush hour traffic," showed substantial variability. The percentage showing a strong preference for driving increased from survey one to survey two and then decreased again in survey three. Examination of the individual responses showed that this was not due to a group of people who changed their responses in this pattern. Rather, it showed up as a complex set of changes in response among a large part of the sample. Since this attitude question had been a statistically significant predictor of the changes in mileage in response to pricing, the regressions were repeated with the responses from the second and third surveys replacing the responses from the first survey. The magnitude and the statistical significance of the estimated coefficients changed with the different variables, but the results were largely consistent across the regressions. Hence, the attitude variables appear to be useful in predicting how people will respond to price incentives, but caution must be used when gathering and using attitude information.

The initial data was analyzed for changes in total rush hour mileage, but the data is available separately for each weekday by morning and evening rush hours. Examination of this data revealed that there was relatively little difference between the morning and evening responses but that there were relatively large differences by day of the week, with Fridays showing the least reduction in rush hour mileage. This implies that pricing may have to vary by day of the week to achieve efficient changes in behavior.

One key aspect of the experiment was to replace the fuel tax with a flat mileage fee. The mileage fee was calculated to be approximately revenue neutral with respect to the fuel tax. However, this means that the mileage fee would be greater than the fuel tax for fuel efficient vehicles and less than the fuel tax for vehicles getting low mileage per gallon. The EPA mileage estimate for each vehicle was used as an explanatory variable to determine if this change in price 
affected how drivers responded to the mileage charge. Cars with high EPA ratings were found to be driven more in the baseline period, but the EPA rating had very small effects on the changes in driving behavior. This implies that the small difference between the fuel tax and the mileage fee does not seem to affect driver responses.

Preliminary analysis of the experiment results found that access to transit affected people's response to pricing. However, the measure used was a self-reported estimate of distance to "transit that will take you where you want to go." Since this is not a commonly defined measure, household addresses were used to identify actual distance to transit services and various measures of transit service availability. The measures of transit service available were not found to affect people's response to the mileage charges, but actual distance to any transit service or to frequent transit service did have a statistically significant effect on the changes in rush hour miles in response to the prices. There was also an effect on changes in total mileage, but it was not statistically significant.

Another finding from the preliminary analysis was that household income did affect the amount of baseline driving and the response to prices in the directions expected, but most results were not statistically significant. However, the household income variable was simply a dummy variable representing whether household income exceeded $\$ 40,000$. The income data from the surveys is actually divided into four income groups, so the additional data was used to refine the analysis. The implication of the different groupings is that the effect of household income on level of baseline driving and changes in driving in response to prices show substantial differences across income ranges. Lower-income households show substantially less baseline driving, but show less reduction in driving than the next highest income group. These differences by income group imply that better understanding of the relationship between income and changes in driving habits will improve estimates of the changes that are likely to occur in response to mileage prices.

The results from this study were broadly compared to the findings from some other studies that examined either mileage fees or congestion pricing. Where comparisons could be made, there was substantial consistency in the findings and estimated magnitude of responses to prices 


\subsection{INTRODUCTION}

The Oregon Department of Transportation (ODOT) tested an innovative technological system designed to replace fuel taxes with mileage fees. Vehicles were equipped with an electronic device that kept track of total miles driven in various categories based on time and location of travel. When these vehicles were fueled at participating stations, the vehicle transferred data on mileage by category. For approximately 4.5 months, the participants were instructed to simply fill up at a participating station at least twice per month. This is referred to as the baseline data collection period. At the end of the baseline phase, participants were assigned to one of three groups: Control, Vehicle Miles Traveled (VMT), or Rush Hour (RH). During the test phase, Control vehicles were instructed to continue fueling at participating stations on a regular basis, but the vehicles in the other two groups were subject to mileage fees as a replacement for the state fuel tax. When these vehicles were fueled at a participating station, the billing system would calculate a mileage fee and deduct the fuel tax at the pump. In the test, drivers in the VMT group were charged a flat fee per mile and drivers in the RH group were charged differential fees that were higher for travel in the Portland metropolitan area during weekday peak hours and lower for other travel. In addition to the data on mileage by category, participants were surveyed three times in order to collect demographic information about each household and gather attitudinal information from the respondent for the household. Only one person per household participated in the surveys. See Rufolo and Kimpel (2008) for a complete description of the experiment and initial findings.

\subsection{APPROACH}

The initial analysis identified some issues that suggested further study, and the data set offered opportunities for analyses that could not be completed as part of the initial review. This project was organized around the data set, so the specific topics covered are less related than would be typical for such a research project, but the information gained helps explain the behavioral response to the mileage fees.

This was intended to be an exploration of how the data collected during the Oregon Mileage Fee Experiment could be used to extend the analysis of factors affecting behavioral changes in response to mileage fees. The research effort was started as a broad analysis of various potential factors and then additional analysis was concentrated in areas showing the most promise. The first item analyzed was the responses and changes in responses related to attitudes between the three surveys. The initial evaluation of the survey responses revealed a perplexing change in response, from survey to survey, to the statement "Offered a choice between convenient public transportation and taking a car, I would always drive a car, even in rush hour traffic." This was of interest both because the attitude response appeared to be a significant determinant of some behavior changes and because the changes might indicate that there were other inconsistencies in the attitude data. This could affect our understanding of how attitudes might be used to predict behavioral changes. The preliminary analysis showed great consistency in the responses to most questions across the surveys. Further analysis was generated related to the one response that 
showed puzzling changes between the surveys. The pattern of changes was identified, but there did not appear to be a clear explanation for the changes. Further, the differences across the surveys had a limited impact on the estimated effect of the attitude on behavioral responses. There did not seem to be much benefit in further analysis of survey response consistency.

Another concern was that the change from a fuel tax to a mileage fee would increase the cost of travel for fuel-efficient cars and reduce it for cars with low fuel efficiency. The EPA estimated mileage for each vehicle was added to the data set to determine if there was an effect of such differences. The analysis indicated that the effect was minor and not statistically significant. This precluded further analysis of how these differences might be affected by attitudes, demographic variables, and so on since there was no effect to analyze.

Completed regression analysis showed that the self-reported distance to "the nearest bus or rail stop that could take you places you want to go" had a moderate and close to statistically significant effect on the changes in behavior. The initial approach to refining the analysis of the effect of transit on behavioral changes focused on the measures of quality of service available. Various measures of transit service at a variety of distances from the residence were used to determine if there was any effect of transit service on the changes in behavior. The surprising result was that the amount of service did not seem to be important in determining behavioral responses. Since the preliminary analysis provided evidence that the self-reported measure of transit within four blocks had some explanatory power with respect to the changes in miles driven, it was decided to focus on more direct measures of distance to transit stops rather than on the amount of transit service available. The distance measures turned out to have the most explanatory power. The analysis was expanded to compare various measures of actual distance to transit with the self-reported measures. This provided some of the more important contributions of the project by generating measures of how access to transit interacted with mileage fees to change miles driven.

Various socio-demographic measures were analyzed for effect on miles driven. The further refinement of the income data provided some interesting insight into the differences in effects for different income groups. The primary finding was that the effect of income was not monotonic, with low-income households changing their miles driven less than some of the higher income groups. This may be due to their driving fewer miles to begin with, and this seems worthy of further analysis. Unfortunately, the limited income data and small sample size prevented further meaningful analysis.

It was hoped that the public use data set from the Puget Sound study would be available to generate some comparisons with the data from this study. Aggregate statistical analysis from the Puget Sound study had been published, but the raw data was not available. Since the data had not been released, the results from this study related to changes in mileage were compared with the published results from the Puget Sound study and several other studies that used VMT based fees. While many of the results from other studies were limited due to sample sizes and other considerations, where data was available it was largely consistent with the results from this study as to how drivers change their behavior when faced with VMT charges. However, this is another area where future research that makes more direct comparisons would be useful. 


\section{$1.2 \quad$ REPORT OUTLINE}

Chapter 2 explains the basic data set and the additional data generated for this project.

Chapter 3 provides the additional analysis of consistency in the survey responses. Changes in the response to attitude statements were analyzed across the three surveys. One response had been statistically significant in the initial analysis, but showed substantial variation across the surveys, so the statistical analysis was repeated with the responses from the other two surveys to see if this affected the usefulness of the attitude data in predicting changes in behavior.

Chapter 4 addresses the concern about the VMT fee having a differential impact on vehicles with different fuel efficiencies. EPA estimates of miles per gallon by vehicle were entered into the data set to analyze whether these differences affected the response to the mileage fees.

Chapter 5 examines the more detailed information on changes in rush hour mileage by day and by morning versus evening. The initial analysis focused on changes in total rush hour mileage, but separate totals were collected for the morning and evening rush hours for each weekday. Differences in response between the morning and evening and by day of the week are presented and discussed.

Chapter 6 reports on more extensive analysis of the relationship between availability of transit service and the changes in behavior in response to the mileage fees. Recent discussions related to the use of pricing to manage road systems have raised questions about the impact that it will have on transit usage as well as how the availability of transit would affect the behavioral changes caused by pricing.

Chapter 7 examines the differences in response to the mileage fees by income in more detail than was possible in the initial analysis. The income data for the participants in the experiment is very limited, indicating whether total household income was less than $\$ 20,000$ per year, between $\$ 20,000$ and $\$ 40,000$, between $\$ 40,000$ and $\$ 60,000$, or greater than $\$ 60,000$. The preliminary statistical analysis simply split the group into above or below $\$ 40,000$. Since there is substantial interest in the affect of income differences on the response to pricing, the more complete data was analyzed.

Finally, other studies have focused on the impact of various types of mileage fees on changes in mileage. Chapter 8 reports on similarities and differences in findings between this study and some other experiments in mileage fees. 


\subsection{DATA}

\subsection{MILEAGE DATA}

Data from the experiment was created as follows. Each vehicle was equipped with a GPS device that allowed mileage to be tracked by zone, where a zone is defined by location and time. The only data generated by the system was the mileage by zone. The geographic delineation of zones were 1) the area within the Portland Urban Growth Boundary, which was used to define the zone for rush hour charges, 2) the rest of Oregon, 3) outside of Oregon, and 4) areas with no GPS signal. Time delineation of zones included the a.m. and p.m. rush hours by weekday for travel inside the Portland Urban Growth Boundary, and weekday and weekend differentiation. Zones included separate totals for each weekday morning and evening rush hour within the Portland Urban Growth Boundary.

Data from each vehicle was predominately collected when the vehicle was fueled at a participating service station. This resulted in data being collected at widely variable times. Hence, the data is analyzed in terms of miles per day or miles per weekday. All vehicles were simply instructed to fuel regularly at the participating stations for about 4.5 months. This is referred to as the baseline data. At the end of this time, the vehicles were assigned to one of two experimental groups or to a control group. Vehicles in the first experimental group, the VMT group, were charged a flat mileage fee of 1.23 cents per mile for all miles driven in Oregon and they received a reduction at the pump or a refund for state gasoline taxes. Participants in the second experimental, the RH group, were charged 10 cents per mile for miles driven in the congestion zone during peak periods on non-holiday weekdays, but only .43 cents per mile for other mileage in Oregon. They also received either a reduction at the pump or a refund of state gasoline taxes.

Each vehicle in the experimental groups was given an endowment account at the beginning of the experiment that was based on the mileage driven during the baseline. Mileage charges were deducted from this account, with any balance paid to the participant at the end of the experiment. If the mileage charge exceeded the endowment, the participant did not have to pay the difference. This procedure gave participants a financial incentive similar to that of actual charging without deterring them from participating in the experiment due to the potential cost. There was also a small control group that simply continued to pay normal fuel charges (including the state gas tax), but they uploaded mileage data when they purchased fuel at one of the participating stations.

\subsection{SURVEY DATA}

In addition to the mileage data, one participant from each household responded to three surveys which included certain demographic information as well as information on the respondent's attitudes. The surveys were conducted at the beginning, midpoint, and end of the experiment. 
They were conducted by telephone, and the survey research firm created a database for each survey. For this study, there were several augmentations to the survey database. The survey response rates were high, but there were always some non-response households. After the first survey, ODOT obtained written responses to the survey from some of the non-respondents, but this data was not added to the database. So, the written responses were coded and added.

Address data that included street information helped determine where most houses were located. A number of households could not be located due to the use of PO Box addresses or other problems with the address data. Of the 168 households that provided useable data for the analysis, 151 were located using a GIS. Figure 1 shows the distribution of the households within the Portland metropolitan area. Based on the recruitment method and the requirement that participants fuel regularly at one of two service stations located on Portland's eastside (identified in the figure by two black circles that represent one mile distance buffers around the stations), it was expected that there would be a high concentration of households near these locations. As the map shows, there is actually a fairly wide distribution, although there is clearly an orientation towards the service stations. Nevertheless, the wide distribution generated differences in access to transit and to the amount of service available. The location data was then augmented with information related to the availability of transit service.

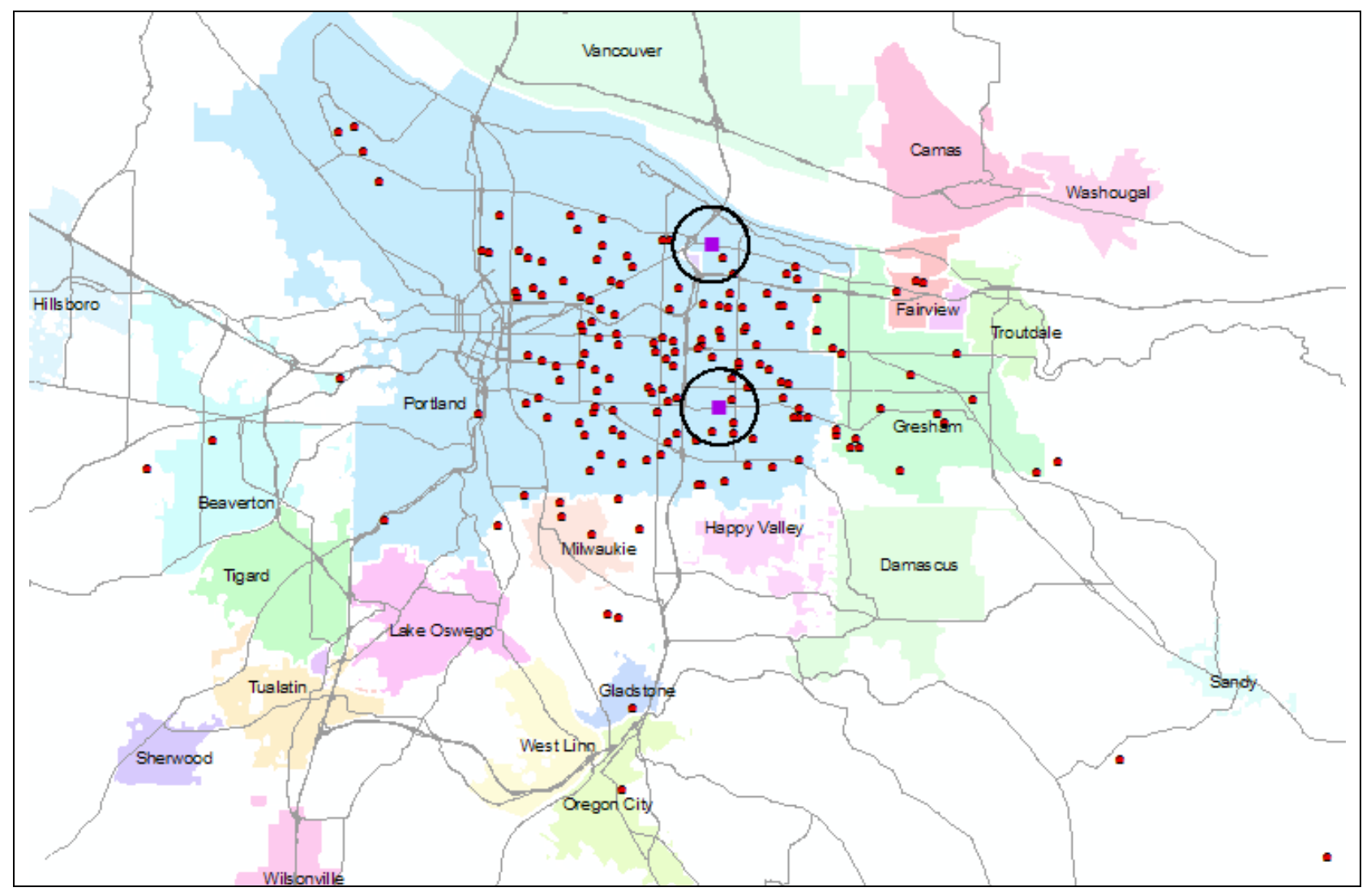

Figure 2.1: Location of Study Participants 
Information from TriMet, the local transit agency, was used to generate several variables that related transit service to residential location. The first was simply distance to the nearest transit stop. The next measures relate to the number of bus routes or rail lines that could be reached within various distances from the residence. This report only considers service within onequarter mile since other distance measures yielded results similar to those for the quarter-mile distance. Hence, there is a variable representing the number of unique transit routes that could be accessed within one-quarter mile and another that represents the number of frequent service transit routes within a quarter mile. TriMet has 19 frequent service bus routes and light rail lines operating at headways of 15 minutes or less during the day, seven days a week. The frequent service bus routes carry over $50 \%$ of TriMet riders. The agency also targets these routes for service quality enhancements in the form of low floor buses, stop amenities, and traffic signal priority.

\subsection{EPA MILEAGE DATA}

One concern with the VMT experiment was that while the price was set to be revenue neutral on average, it would create higher and lower costs per mile for different vehicles. A vehicle that achieved approximately 20 miles per gallon would have a mileage fee that was essentially equivalent to the state gas tax on a per mile basis. However, more fuel efficient cars would have a mileage charge that was greater than the equivalent fuel tax while less fuel efficient cars would have a mileage charge that was less than the equivalent gas tax. ODOT had collected EPA mileage data by vehicle for the vehicles registered in the experiment. This data is available by vehicle make, model, and year. The appropriate estimate for each vehicle was entered into the database. There are various concerns about using the EPA estimates since they do not necessarily reflect actual driving conditions nor do they reflect the effect of differences in individual driving habits. However, they provide a consistent set of estimates across vehicles. 


\subsection{ATTITUDES EXPRESSED IN THE SURVEYS}

\subsection{CONSISTENCY OF ATTITUDE RESPONSES}

One consideration in the experiment's design was to see if various attitudes expressed by participants could be used to explain their later changes in behavior or failure to change behavior in response to pricing incentives. Several of these attitude variables were used in the statistical analysis of changes in behavior in response to the pricing experiments and proved to have predictive power. However, preliminary analysis of the survey results showed that there appeared to be inconsistencies in some of the responses across the surveys. One concern with using attitude responses is the possibility that people may alter their response based on what they think is the "correct" answer. The context of the experiment and timing of the survey may then lead to somewhat biased responses, which in turn would call into question the relationship between the attitudes expressed and the changes in behavior. The survey response to the statement, "Offered a choice between convenient public transportation and taking a car, I would always drive a car, even in rush hour traffic," was a statistically significant factor in how people responded to the mileage fees. Therefore, the changes from survey to survey in this response raised a question of whether the result was a valid interpretation based on the attitudes of the respondent.

There were some changes in respondents among the surveys, and this might have resulted in some of the observed differences in responses. The instructions were for the same person to be the respondent throughout the experiment, but there are clear indications of changes in some cases, such as differences in the gender of the respondent. However, it is noteworthy that the other attitude questions did not show any patterns of differences across the surveys except as noted below.

The survey responses to attitude questions were "strongly agree," "agree," "neither agree nor disagree," "disagree," and "strongly disagree." To make comparisons between surveys, the responses were numbered from one to five. A higher number indicates more agreement with the statement and a lower number indicates more disagreement with the statement. A positive difference in the responses indicates a shift toward agreement with the statement and a negative difference indicates a shift toward disagreement with the statement. Responses to each attitude question were then compared statistically between surveys 1 and 2, 2 and 3, and 1 and 3 . The results of paired t-tests across the survey response are reported in Tables 3.2-3.4. Table 3.1 provides the wording for the statements. Table 3.2 shows the comparison between the first and second surveys, Table 3.3 has the comparison between the second and third surveys, and Table 3.4 shows the comparison between the first and third surveys. For most questions, there was a high level of consistency in responses across the surveys. However, three questions showed statistically significant changes in responses. There was a statistically significant decrease in the percentage who agreed with the statement that "The price of gasoline affects the choices I make about my daily travel." This change occurred between the first and second surveys. There is no 
clear reason for this change, but it may simply reflect people becoming more aware that they did not change their behavior as gas prices started to rise.

\section{Table 3.1 Wording of Attitude Questions}

\begin{tabular}{|l|}
\hline Wording of Attitude Questions \\
\hline $\begin{array}{l}\text { Offered a choice between convenient public transportation and taking a car, I would always drive a car, even in rush } \\
\text { hour traffic. }\end{array}$ \\
\hline Travel time is generally wasted time. \\
\hline If I have to start my car anyway, I might as well drive all the way rather than park and catch the bus or MAX. \\
\hline When I'm going someplace, I think more about how quickly I can get there than how much it will cost. \\
\hline I am willing to pay a toll or tax to support new highways. \\
\hline Getting to work without a car is a hassle. \\
\hline I am uncomfortable driving in heavy traffic. \\
\hline The price of gasoline affects the choice I make about my daily travel. \\
\hline When I need to buy something, I usually prefer to get it at the closest store possible. \\
\hline I can't plan ahead when I go somewhere because my schedule often changes. \\
\hline
\end{tabular}

Table 3.2 Responses from Surveys 1 and 2

\begin{tabular}{|l|c|c|c|}
\hline Household's answer to the same attitude questions asked & \multicolumn{3}{|c|}{ Paired Differences } \\
\cline { 2 - 3 } $\begin{array}{l}\text { at the beginning of the experiment (Survey 1) and in the } \\
\text { middle of the experiment (Survey 2) }\end{array}$ & Mean & t-ratio & Sig. (2-tailed) \\
\hline Always Prefer to Drive & .295 & 2.494 & .014 \\
\hline Travel Time is Wasted Time & .011 & .088 & .930 \\
\hline In Car, Might as Well Drive & -.038 & -.311 & .756 \\
\hline Time More Important than Cost & .060 & .512 & .609 \\
\hline Willing to Pay Toll or Tax & .290 & 2.230 & .027 \\
\hline Commuting without Car is Hassle & -.115 & -.765 & .445 \\
\hline Uncomfortable in Heavy Traffic & .104 & .976 & .330 \\
\hline Gas Price Affects Choices & -.432 & -4.292 & .000 \\
\hline Prefer Closest Store & .055 & .499 & .618 \\
\hline Can't Plan Ahead & .131 & 1.161 & .247 \\
\hline
\end{tabular}

Table 3.3 Responses from Surveys 2 and 3

\begin{tabular}{|l|c|c|c|}
\hline Household's answer to the same attitude questions asked & \multicolumn{3}{|c|}{ Paired Differences } \\
\cline { 2 - 3 } $\begin{array}{l}\text { in the middle of the experiment (Survey 2) and at the } \\
\text { end of the experiment (Survey 3) }\end{array}$ & Mean & t-ratio & Sig. (2-tailed) \\
\hline Always Prefer to Drive & -.361 & -3.350 & .001 \\
\hline Travel Time is Wasted Time & -.0227 & -.186 & .853 \\
\hline In Car, Might as Well Drive & .101 & .839 & .403 \\
\hline Time More Important than Cost & .107 & .932 & .352 \\
\hline Willing to Pay Toll or Tax & .141 & 1.361 & .175 \\
\hline Commuting without Car is Hassle & .197 & 1.418 & .158 \\
\hline Uncomfortable in Heavy Traffic & -.107 & -1.252 & .212 \\
\hline Gas Price Affects Choices & .011 & .110 & .912 \\
\hline Prefer Closest Store & .197 & 1.695 & .092 \\
\hline Can't Plan Ahead & -.034 & -.329 & .742 \\
\hline
\end{tabular}


Table 3.4 Responses from Surveys 1 and 3

\begin{tabular}{|l|c|c|c|}
\hline Household's answer to the same attitude questions asked & \multicolumn{3}{|c|}{ Paired Differences } \\
\cline { 2 - 3 } $\begin{array}{l}\text { at the beginning of the experiment (Survey 1) and at the } \\
\text { end of the experiment (Survey 3) }\end{array}$ & Mean & t-ratio & Sig. (2-tailed) \\
\hline Always Prefer to Drive & -.062 & -.529 & .598 \\
\hline Travel Time is Wasted Time & -.050 & -.444 & .658 \\
\hline In Car, Might as Well Drive & .107 & .884 & .378 \\
\hline Time More Important than Cost & .186 & 1.473 & .142 \\
\hline Willing to Pay Toll or Tax & .463 & 3.772 & .000 \\
\hline Commuting without Car is Hassle & .102 & .736 & .462 \\
\hline Uncomfortable in Heavy Traffic & -.050 & -.523 & .602 \\
\hline Gas Price Affects Choices & -.429 & -3.912 & .000 \\
\hline Prefer Closest Store & .192 & 1.718 & .088 \\
\hline Can't Plan Ahead & .073 & .722 & .471 \\
\hline
\end{tabular}

The second statistically significant change was an increase in agreement with the statement, "I am willing to pay a toll or tax to support new highways." This may have been due to the familiarity with the mileage fee system that was developed or it may have been due to people becoming aware that the experiment was related to a system to collect a mileage fee. The initial interpretation was that people became more comfortable with the fee system and thus were more inclined to agree as the experiment progressed; however, it may be that some people were simply changing their responses based on what they thought the experimenters would like to hear.

The most perplexing change was in response to the statement, "Offered a choice between convenient public transportation and taking a car, I would always drive a car, even in rush hour traffic." There was a large and statistically significant increase in agreement with this statement between surveys 1 and 2, then an equally large and statistically significant reduction between surveys 2 and 3, so that there was almost no difference in response between surveys 1 and 3 . One possibility is that people altered their responses based on changing perceptions of what the experiment was designed for. At the beginning of the experiment, participants were not told about the pricing system, but they were told that the devices would keep a total of their mileage and report mileage whenever they purchased gas at a participating station. It would not be implausible to think that some might interpret this as a system that would monitor driving so as to try to reduce mileage. Hence, the bias would be to respond against the statement.

At the end of the baseline data collection, the participants still had not been informed of the nature of the experiment and may have concluded that it was simply a method of monitoring mileage. They may have felt more comfortable responding that they preferred to drive. At the end of the experiment, participants in the two mileage fee groups were well aware of the intent to use the system to collect mileage fees, so the bias may have switched back toward saying that they do not prefer to drive. This is, of course, simply speculation, so a detailed analysis of the response changes to this question was conducted.

\subsection{ATTITUDES TOWARD DRIVING}

The findings were very surprising. To make the analysis manageable, the "strongly agree" and "agree" responses were combined to "agree," and the "strongly disagree" and "disagree" 
responses were combined to "disagree." Despite this combination of responses, there was little consistency in responses across the sample. As seen in Table 3.5, only 43 of the 143 households consistently agreed or disagreed with the statement across the three surveys. If we ignore all responses that contained "neither agree nor disagree" and N/A, we still have 72 households with substantial changes in their response to this question. There were 17 households that gave the response disagree/agree/disagree, which would be consistent with the hypothesized bias discussed above; however, 13 households had the response pattern agree/disagree/agree, which would be the opposite of the hypothesized bias. These changes come close to canceling each other out. Instead, we see that 42 households changed from either agree to disagree or disagree to agree. However, the households that changed from agree to disagree were fairly evenly divided between switching at survey 2 and survey 3 whereas 17 of the 20 households that switched from disagree to agree did so at the second survey.

Table 3.5 Response Patterns

\begin{tabular}{|l|r|l|r|}
\hline Answered the following combinations at Survey 1, Survey 2 \& Survey 3 \\
\hline Combination & Number of HH & Combination & $\begin{array}{r}\text { Number of } \\
\text { HH }\end{array}$ \\
& & & 24 \\
\hline Agree/Agree/Agree & 19 & Disagree/ Disagree/Disagree & 17 \\
\hline Agree/Disagree/Agree & 13 & Disagree/Agree/Disagree & 3 \\
\hline Agree/Agree/Disagree & 9 & Disagree/ Disagree/Agree & 17 \\
\hline Agree/Disagree/Disagree & 13 & Disagree/ Agree/Agree & 1 \\
\hline Agree/Indifferent/Agree & 4 & Disagree/Indifferent/Disagree & 1 \\
\hline Agree/Agree/Indifferent & 2 & Disagree/Indifferent/Agree & 1 \\
\hline Agree/Indifferent/Indifferent & 1 & Disagree/Agree/Indifferent & 1 \\
\hline Agree/Indifferent/Disagree & 3 & Disagree/Agree/ N/A & 2 \\
\hline Indifferent/Disagree/Disagree & 5 & Disagree/ N/A/Disagree & 1 \\
\hline Indifferent/Agree/Indifferent & 2 & Indifferent/Agree/Agree & 143 \\
\hline Indifferent/Agree/Disagree & 1 & N/A/Agree/Disagree & 1 \\
\hline All Other Combinations & 0 & Total Number of Households & \\
\hline
\end{tabular}

\subsection{EFFECT ON STATISTICAL ANALYSIS}

Since the regression analysis indicated that the response to this attitude question was statistically significant in explaining behavior, the responsiveness was tested by checking to see if the responses on the different surveys yielded different conclusions about the effect of attitude on behavior. Using the responses from the first survey, the coefficients were small and nowhere near significant in explaining any of the baseline driving. Many of the following regression results use essentially the same variables with one variable changed. For ease of interpretation, the results for the key variable in each table are in bold type. Table 3.6 shows that using the response to the question in the second survey results in a large and statistically significant relationship to baseline rush hour driving. Those expressing this attitude in the second survey drove almost two additional rush hour miles per day than those who did not express this attitude. Yet there was still no relationship to total miles. Table 3.7 shows that using the responses to the third survey yields results similar to the response from the second survey but not statistically 
significant for any of the regressions. This would be consistent with the interpretation that the responses to the second survey were the most accurate in explaining attitudes during the baseline data collection period.

Table 3.6 Baseline Period- Rush Hour Miles per Vehicle per Weekday, Total Oregon Miles per Vehicle per Day, and Total Miles per Vehicle per Day- Survey 2

\begin{tabular}{|c|c|c|c|}
\hline Variables & Rush Hour & Oregon & Total Miles \\
\hline \multirow[t]{2}{*}{ Number of Vehicles in $\mathrm{HH}$} & $-3.347 * *$ & $-7.351 * *$ & $-7.818 * *$ \\
\hline & $(-5.199)$ & $(-4.004)$ & $(-3.742)$ \\
\hline \multirow{2}{*}{ Number of Persons in $\mathrm{HH}$} & $1.277 *$ & $5.879 * *$ & $5.758 * *$ \\
\hline & $(2.479)$ & $(4.001)$ & $(3.443)$ \\
\hline \multirow{2}{*}{ Gender Dummy (Male) } & -0.702 & -1.715 & -2.123 \\
\hline & $(-.956)$ & $(-.819)$ & $(-.890)$ \\
\hline \multirow{2}{*}{ At Least 1 Person in HH Emp. FT Dummy } & 0.639 & 1.895 & 1.751 \\
\hline & $(0.831)$ & $(0.864)$ & $(0.702)$ \\
\hline \multirow{2}{*}{ Always Drive, Even if Transit Available Dummy } & $1.948 * *$ & -0.307 & -0.466 \\
\hline & $(2.766)$ & $(-.153)$ & $(-.204)$ \\
\hline \multirow{2}{*}{ Commuting w/o Car is Hassle Dummy } & $2.066^{* *}$ & $5.019^{*}$ & 4.733 \\
\hline & $(2.742)$ & $(2.336)$ & $(1.936)$ \\
\hline \multirow{2}{*}{ Need Car b/c Sched. Changes Often Dummy } & 0.128 & 3.115 & 3.371 \\
\hline & $(0.159)$ & $(1.349)$ & $(1.283)$ \\
\hline \multirow{2}{*}{ Transit Access LT 4 Blocks Dummy } & $-2.582 * *$ & -1.798 & -3.447 \\
\hline & $(-3.624)$ & $(-.885)$ & $(-1.491)$ \\
\hline \multirow{2}{*}{ Children Under 16 in HH Dummy } & $1.856^{*}$ & 1.775 & 1.452 \\
\hline & $(2.316)$ & $(0.777)$ & $(0.558)$ \\
\hline \multirow{2}{*}{ Speed More Imp't Than Cost Dummy } & 0.605 & 0.417 & 0.855 \\
\hline & $(0.863)$ & $(0.209)$ & $(0.375)$ \\
\hline \multirow{2}{*}{ WTP Tax/Toll Dummy } & 0.568 & 0.687 & 0.469 \\
\hline & $(0.836)$ & $(0.355)$ & $(0.212)$ \\
\hline \multirow{2}{*}{ Gas Price Affects Travel Choices Dummy } & 1.096 & -0.057 & -0.599 \\
\hline & $(1.486)$ & $(-.027)$ & $(-.250)$ \\
\hline \multirow{2}{*}{ HH Income $\$ 40 \mathrm{~K}+$ Dummy } & $2.848 * *$ & 3.993 & $6.329 *$ \\
\hline & $(3.397)$ & $(1.671)$ & $(2.327)$ \\
\hline \multirow{2}{*}{ Constant } & $4.809 * *$ & $20.088 * *$ & $24.636 * *$ \\
\hline & $(3.295)$ & $(4.827)$ & $(5.201)$ \\
\hline Adj. $R^{2}$ & 0.268 & 0.14 & 0.119 \\
\hline $\mathrm{N}$ & 191 & 191 & 191 \\
\hline
\end{tabular}

** Significant at the $99 \%$ level of confidence

* Significant at the $95 \%$ level of confidence

Table 3.7 Baseline Period- Rush Hour Miles per Vehicle per Weekday, Total Oregon Miles per Vehicle per Day, and Total Miles per Vehicle per Day- Survey 3

\begin{tabular}{|c|c|c|c|}
\hline Variables & Rush Hour & Oregon & Total Miles \\
\hline Number of Vehicles in $\mathrm{HH}$ & $-3.218 * *$ & $-8.598 * *$ & $-9.173 * *$ \\
\hline
\end{tabular}




\begin{tabular}{|c|c|c|c|}
\hline & $(-4.950)$ & $(-3.699)$ & $(-3.267)$ \\
\hline \multirow{2}{*}{ Number of Persons in $\mathrm{HH}$} & $1.423 * *$ & $5.296^{* *}$ & $4.756^{*}$ \\
\hline & $(2.763)$ & $(2.876)$ & $(2.138)$ \\
\hline \multirow{2}{*}{ Gender Dummy (Male) } & -1.063 & 0.814 & 1.291 \\
\hline & $(-1.494)$ & $(0.32)$ & $(0.42)$ \\
\hline \multirow{2}{*}{ At Least 1 Person in HH Emp. FT Dummy } & 0.468 & -0.01 & -0.887 \\
\hline & $(0.588)$ & $(-.004)$ & $(-.258)$ \\
\hline \multirow{2}{*}{ Always Drive, Even if Transit Available Dummy } & 1.147 & 0.166 & -0.479 \\
\hline & $(1.609)$ & $(0.065)$ & $(-.156)$ \\
\hline \multirow{2}{*}{ Commuting w/o Car is Hassle Dummy } & $2.061 * *$ & 1.644 & 0.73 \\
\hline & $(2.767)$ & $(0.617)$ & $(0.227)$ \\
\hline \multirow{2}{*}{ Need Car b/c Sched. Changes Often Dummy } & 0.186 & $5.891 *$ & $6.958^{*}$ \\
\hline & $(0.23)$ & $(2.031)$ & $(1.986)$ \\
\hline \multirow{2}{*}{ Transit Access LT 4 Blocks Dummy } & $-2.174 * *$ & -0.763 & -1.73 \\
\hline & $(-3.088)$ & $(-.303)$ & $(-.569)$ \\
\hline \multirow{2}{*}{ Children Under 16 in HH Dummy } & $2.061^{*}$ & 5.393 & 6.208 \\
\hline & $(2.567)$ & $(1.879)$ & $(1.791)$ \\
\hline \multirow{2}{*}{ Speed More Imp't Than Cost Dummy } & 0.572 & 3.302 & 4.556 \\
\hline & $(0.8)$ & $(1.291)$ & $(1.474)$ \\
\hline \multirow{2}{*}{ WTP Tax/Toll Dummy } & 0.799 & 1.528 & 1.214 \\
\hline & $(1.155)$ & $(0.618)$ & $(0.406)$ \\
\hline \multirow{2}{*}{ Gas Price Affects Travel Choices Dummy } & 1.032 & 0.697 & 0.551 \\
\hline & $(1.406)$ & $(0.265)$ & $(0.174)$ \\
\hline \multirow{2}{*}{ HH Income $\$ 40 \mathrm{~K}+$ Dummy } & $2.882 * *$ & 1.665 & 3.3 \\
\hline & $(3.414)$ & $(0.552)$ & $(0.905)$ \\
\hline \multirow{2}{*}{ Constant } & $4.695 * *$ & $22.587 * *$ & $27.875 * *$ \\
\hline & $(3.204)$ & $(4.31)$ & $(4.404)$ \\
\hline Adj. $\mathrm{R}^{2}$ & 0.248 & 0.095 & 0.062 \\
\hline $\mathrm{N}$ & 190 & 190 & 190 \\
\hline
\end{tabular}

** Significant at the $99 \%$ level of confidence

* Significant at the $95 \%$ level of confidence

The response from the first survey in the initial analysis showed a large (around four miles per day) and statistically significant effect in changes in total Oregon miles and Total miles driven. Yet when we use the responses from the second and third surveys to examine the changes in mileage that occurred during the experiment, the estimated magnitudes of the impact of the attitude on changes in behavior are reduced. Further, the only statistically significant effect is seen in the relationship between the attitude and changes in total miles using the second survey response. These results are shown in tables 3.8 and 3.9.

The magnitude and statistical significance of the coefficients in explaining changes in Total Oregon miles and in Total miles are much reduced. This implies that the initial response was a better indicator of actual attitudes than the later ones in explaining the changes in behavior. Hence, there is some inconsistency in which survey best explains behavior between the findings related to baseline miles driven and changes in miles driven. There appears to be enough consistency among the responses that they yield information on how behavior will change, but the response changes do raise questions about how accurately they reflect actual attitudes. This implies that attitudes may be important in predicting how a particular population will respond to prices but that care must be taken in determining attitudes. 
Table 3.8 Change in Rush Hour Miles per Vehicle per Weekday, Change in Total Oregon Miles per Vehicle per Day, and Change in Total Miles per Vehicle per Day- Survey 2

\begin{tabular}{|c|c|c|c|}
\hline Variables & Rush Hour & Oregon & Total Miles \\
\hline \multirow{2}{*}{ Number of Vehicles in HH } & 0.632 & 0.68 & 1.037 \\
\hline & $(1.613)$ & $(0.614)$ & $(0.74)$ \\
\hline \multirow{2}{*}{ Number of Persons in $\mathrm{HH}$} & -0.459 & $-3.184 * *$ & $-2.898 * *$ \\
\hline & $(-1.494)$ & $(-3.665)$ & $(-2.639)$ \\
\hline \multirow{2}{*}{ Gender Dummy (Male) } & 0.185 & 2.098 & 2.956 \\
\hline & $(0.421)$ & $(1.684)$ & $(1.876)$ \\
\hline \multirow{2}{*}{ At Least 1 Person in HH Emp. FT Dummy } & 0.162 & 0.674 & 0.864 \\
\hline & $(0.35)$ & $(0.514)$ & $(0.521)$ \\
\hline \multirow{2}{*}{ Always Drive, Even if Transit Available Dummy } & 0.161 & 1.509 & $3.455 *$ \\
\hline & $(\mathbf{0 . 3 8})$ & $(1.261)$ & (2.284) \\
\hline \multirow{2}{*}{ Commuting w/o Car is Hassle Dummy } & -0.68 & -0.748 & -1.333 \\
\hline & $(-1.505)$ & $(-.585)$ & $(-.824)$ \\
\hline \multirow{2}{*}{ Need Car b/c Sched. Changes Often Dummy } & -0.736 & -0.604 & 0.935 \\
\hline & $(-1.522)$ & $(-.441)$ & $(0.541)$ \\
\hline \multirow{2}{*}{ Transit Access LT 4 Blocks Dummy } & -.715 & -2.075 & -1.686 \\
\hline & $(-1.685)$ & $(-1.729)$ & $(-1.111)$ \\
\hline \multirow{2}{*}{ Children Under 16 in HH Dummy } & 0.747 & 1.39 & 2.643 \\
\hline & $(1.562)$ & $(1.028)$ & (1.546) \\
\hline \multirow{2}{*}{ Speed More Imp't Than Cost Dummy } & -0.005 & 0.531 & 1.118 \\
\hline & $(-.011)$ & $(0.449)$ & $(0.747)$ \\
\hline \multirow{2}{*}{ WTP Tax/Toll Dummy } & 0.157 & -0.161 & 0.719 \\
\hline & $(0.387)$ & $(-.141)$ & $(0.495)$ \\
\hline \multirow{2}{*}{ Gas Price Affects Travel Choices Dummy } & -0.343 & -0.838 & -0.641 \\
\hline & $(-.769)$ & $(-.665)$ & $(-.402)$ \\
\hline \multirow{2}{*}{ HH Income $\$ 40 \mathrm{~K}+$ Dummy } & -0.401 & -0.286 & -0.807 \\
\hline & $(-.794)$ & $(-.201)$ & $(-.447)$ \\
\hline \multirow{2}{*}{ Rush Hour Group Dummy } & $-1.594 * *$ & $-2.475^{*}$ & -2.401 \\
\hline & $(-3.809)$ & $(-2.090)$ & $(-1.604)$ \\
\hline \multirow{2}{*}{ Control Group Dummy } & 0.238 & 1.313 & 1.673 \\
\hline & $(0.26)$ & $(0.507)$ & $(0.511)$ \\
\hline \multirow{2}{*}{ Constant } & 1.529 & 2.391 & -2.035 \\
\hline & $(1.74)$ & $(0.961)$ & $(-.647)$ \\
\hline Adj. $R^{2}$ & 0.106 & 0.05 & 0.029 \\
\hline $\mathrm{N}$ & 191 & 191 & 191 \\
\hline
\end{tabular}

** Significant at the $99 \%$ level of confidence

* Significant at the $95 \%$ level of confidence 
Table 3.9 Change in Rush Hour Miles per Vehicle per Weekday, Change in Total Oregon Miles per Vehicle per Day, and Change in Total Miles per Vehicle per Day- Survey 3

\begin{tabular}{|c|c|c|c|}
\hline Variables & Rush Hour & Oregon & Total Miles \\
\hline \multirow{2}{*}{ Number of Vehicles in HH } & 0.532 & 0.913 & 1.461 \\
\hline & $(1.365)$ & $(0.805)$ & $(1.032)$ \\
\hline \multirow{2}{*}{ Number of Persons in $\mathrm{HH}$} & -0.357 & $-3.364 * *$ & $-2.658^{*}$ \\
\hline & $(-1.179)$ & $(-3.817)$ & $(-2.417)$ \\
\hline \multirow{2}{*}{ Gender Dummy (Male) } & 0.238 & $2.507 *$ & 2.620 \\
\hline & $(0.567)$ & $(2.052)$ & $(1.718)$ \\
\hline \multirow{2}{*}{ At Least 1 Person in HH Emp. FT Dummy } & 0.036 & 0.337 & 0.876 \\
\hline & $(0.076)$ & $(0.246)$ & $(0.512)$ \\
\hline \multirow{2}{*}{ Always Drive, Even if Transit Available Dummy } & 0.134 & 1.41 & 2.182 \\
\hline & $(0.318)$ & $(1.152)$ & $(1.429)$ \\
\hline \multirow{2}{*}{ Commuting w/o Car is Hassle Dummy } & -0.618 & -1.246 & -1.329 \\
\hline & $(-1.406)$ & $(-.975)$ & $(-.833)$ \\
\hline \multirow{2}{*}{ Need Car b/c Sched. Changes Often Dummy } & -0.68 & -0.229 & 1.113 \\
\hline & $(-1.428)$ & $(-.165)$ & $(0.643)$ \\
\hline \multirow{2}{*}{ Transit Access LT 4 Blocks Dummy } & $-.747^{*}$ & -1.837 & -1.407 \\
\hline & $(-1.807)$ & $(-1.528)$ & $(-.938)$ \\
\hline \multirow{2}{*}{ Children Under 16 in HH Dummy } & 0.682 & 1.694 & 2.516 \\
\hline & (1.446) & $(1.234)$ & (1.468) \\
\hline \multirow{2}{*}{ Speed More Imp't Than Cost Dummy } & 0.002 & 0.517 & 0.777 \\
\hline & $(0.006)$ & $(0.423)$ & $(0.509)$ \\
\hline \multirow{2}{*}{ WTP Tax/Toll Dummy } & 0.227 & 0.212 & 1.212 \\
\hline & $(0.558)$ & $(0.179)$ & $(0.82)$ \\
\hline \multirow{2}{*}{ Gas Price Affects Travel Choices Dummy } & -0.351 & -0.904 & -0.949 \\
\hline & $(-.802)$ & $(-.710)$ & $(-.598)$ \\
\hline \multirow{2}{*}{ HH Income $\$ 40 \mathrm{~K}+$ Dummy } & -0.295 & -0.856 & -1.204 \\
\hline & $(-.590)$ & $(-.589)$ & $(-.663)$ \\
\hline \multirow{2}{*}{ Rush Hour Group Dummy } & $-1.587 * *$ & -2.124 & -2.12 \\
\hline & $(-3.877)$ & $(-1.783)$ & $(-1.426)$ \\
\hline \multirow{2}{*}{ Control Group Dummy } & 0.278 & 1.241 & 1.54 \\
\hline & $(0.306)$ & $(0.469)$ & $(0.466)$ \\
\hline \multirow{2}{*}{ Constant } & 1.468 & 2.808 & -2.008 \\
\hline & $(1.684)$ & $(1.107)$ & $(-.634)$ \\
\hline Adj. $R^{2}$ & 0.098 & 0.07 & 0.028 \\
\hline $\mathrm{N}$ & 190 & 190 & 190 \\
\hline
\end{tabular}

** Significant at the $99 \%$ level of confidence

* Significant at the $95 \%$ level of confidence 


\subsection{PRICING AND VEHICLE MPG}

One concern that has been raised with respect to changing from a fuel tax to a mileage fee is that fuel-efficient cars would pay more and less fuel efficient cars would pay less relative to the current distribution of the fuel tax. While this is certainly true, the impact is likely to be small since the magnitude of the state gas tax is small relative to the other costs of driving. Indeed, McMullen and Zhang (2008) find that the distributional impact of the mileage fee is very small. Nevertheless, it is helpful to get empirical information on whether the change in the distribution of the tax burden would affect driving behavior. The most direct test for this is to see if differences in fuel efficiency affected the changes in behavior that resulted from the pricing experiment. In particular, it was hypothesized that vehicles in the VMT group would see the largest effect of this, since the VMT fee would be higher for vehicles that were more fuel efficient than average and be lower for vehicles that were less fuel efficient than average relative to the state gas tax. To test this hypothesis directly, the EPA mileage estimate for each vehicle was entered as a variable.

The first test is whether there is any effect of EPA mileage on baseline driving. As seen in Table 4.1, vehicles with higher EPA mileage estimates appear to be driven somewhat more miles per day than vehicles with lower estimates. The effect is relatively small, and it is not statistically significant. The small positive effect may be due to people who undertake substantial amounts of driving choosing more fuel efficient vehicles.

Table 4.1 Baseline Period- Rush Hour Miles per Vehicle per Weekday, Total Oregon Miles per Vehicle per Day, and Total Miles per Vehicle per Day With EPA Estimates

\begin{tabular}{|c|c|c|c|}
\hline Variables & Rush Hour & Oregon & Total Miles \\
\hline \multirow{2}{*}{ Number of Vehicles in $\mathrm{HH}$} & $-2.908 * *$ & $-6.967 * *$ & $-7.427 * *$ \\
\hline & $(-4.465)$ & $(-3.046)$ & $(-2.693)$ \\
\hline \multirow{2}{*}{ Number of Persons in $\mathrm{HH}$} & $1.404 * *$ & $4.836^{* *}$ & $4.261^{*}$ \\
\hline & $(2.744)$ & $(2.692)$ & $(1.967)$ \\
\hline \multirow{2}{*}{ Gender Dummy (Male) } & -1.058 & .877 & 1.420 \\
\hline & $(-1.467)$ & $(.347)$ & $(.465)$ \\
\hline \multirow{2}{*}{ HH Income $\$ 40 \mathrm{~K}+$ Dummy } & $2.548 * *$ & .971 & 2.380 \\
\hline & $(3.045)$ & $(.331)$ & $(.671)$ \\
\hline \multirow{2}{*}{ At Least 1 Person in HH Emp. FT Dummy } & .588 & -.270 & -.775 \\
\hline & $(.745)$ & $(-.097)$ & $(-.232)$ \\
\hline \multirow{2}{*}{ Always Drive, Even if Transit Available Dummy } & .469 & -.248 & .371 \\
\hline & $(.652)$ & $(-.098)$ & $(.122)$ \\
\hline \multirow{2}{*}{ Commuting w/o Car is Hassle Dummy } & $2.381 * *$ & 2.812 & 1.591 \\
\hline & $(3.093)$ & $(1.040)$ & $(.488)$ \\
\hline \multirow{2}{*}{ Need Car b/c Sched. Changes Often Dummy } & .403 & $5.707 *$ & 6.621 \\
\hline & $(.502)$ & $(2.026)$ & $(1.949)$ \\
\hline \multirow{2}{*}{ Transit Access LT 4 Blocks Dummy } & $-2.174 * *$ & -.739 & -1.939 \\
\hline & $(-3.068)$ & $(-.297)$ & $(-.646)$ \\
\hline
\end{tabular}




\begin{tabular}{|l|c|c|c|}
\hline \multirow{2}{*}{ Children Under 16 in HH Dummy } & $1.981^{*}$ & 5.371 & 5.985 \\
\cline { 2 - 4 } & $(2.452)$ & $(1.893)$ & $(1.749)$ \\
\hline \multirow{2}{*}{ Speed More Imp't Than Cost Dummy } & .622 & 2.789 & 3.757 \\
\cline { 2 - 4 } & $(.880)$ & $(1.124)$ & $(1.256)$ \\
\hline \multirow{2}{*}{ WTP Tax/Toll Dummy } & .617 & 1.319 & 1.255 \\
\cline { 2 - 4 } & $(.899)$ & $(.547)$ & $(.432)$ \\
\hline \multirow{2}{*}{ Gas Price Affects Travel Choices Dummy } & 1.267 & 1.502 & 1.439 \\
\hline \multirow{2}{*}{ EPA Mileage Rating } & $(1.686)$ & $(.570)$ & $(.452)$ \\
\hline \multirow{2}{*}{ (Constant) } & $\mathbf{. 0 5 8}$ & $\mathbf{. 3 5 8}$ & $\mathbf{. 3 7 4}$ \\
\hline & $\mathbf{( . 9 7 7 )}$ & $\mathbf{( 1 . 7 2 0 )}$ & $\mathbf{( 1 . 4 9 0 )}$ \\
\hline Adj. $\mathrm{R}^{2}$ & 3.121 & 13.242 & $17.789^{*}$ \\
\hline $\mathrm{N}$ & $(1.496)$ & $(1.808)$ & $(2.014)$ \\
\hline
\end{tabular}

** Significant at the $99 \%$ level of confidence

* Significant at the $95 \%$ level of confidence

If people did take account of the price differential between the gas tax and the mileage fee, then vehicles with high fuel efficiency would show a greater reduction or smaller increase in miles driven than vehicles with lower fuel efficiency. Regressions were run using the EPA mileage estimates as an explanatory variable for the changes in miles driven for all vehicles. There is a small decrease in miles driven for higher mileage EPA vehicles which is consistent with the expectation, but it is very small and not statistically significant. Looking at the VMT group alone, the coefficients imply that the higher EPA mileage vehicles showed a greater increase or smaller decrease in Oregon and total mileage than the lower EPA vehicles. These coefficients also are small and are not statistically significant, but the implication is that these small differences do not seem to have affected the changes in driving for this group. There was a small but statistically significant decrease for total miles with higher EPA vehicles for the RH group. This is something of an anomaly since the off-peak mileage charge for these vehicles was on average less than half of the gas tax per mile. However, there was still a relative increase for the higher EPA vehicles, so the result is consistent with expectations. There was virtually no effect on rush hour miles for this group, and this would also be consistent since the 10-cent-per-mile charge for this driving was many times the gas tax per mile. 


\subsection{VARIATIONS IN RUSH HOUR MILEAGE CHANGES}

One of the notable findings in the initial analysis of the effect of mileage charges was the relatively large and statistically significant reduction in rush hour mileage associated with the use of congestion pricing. Vehicles subjected to the 10-cent-per-mile charge were found to reduce their rush hour mileage by $13 \%$ compared to baseline mileage and by $22 \%$ compared to the VMT group. In addition to the change in total mileage, the data on rush hour mileage was collected separately for each weekday and for a.m. and p.m. rush hours. Hence, it is possible to examine the changes in behavior in more detail to see if there is a uniform reduction in rush hour mileage or if there are patterns to the changes.

Table 5.1 shows the a.m. and p.m. comparisons for each of the groups. The data for the control group is presented for completeness, but the small sample size prevents any substantive conclusions. For the VMT and RH groups, there are fairly similar changes between the a.m. and p.m. totals, indicating that the ability to adjust behavior does not seem to be affected by the direction of travel. As noted in the initial analysis, the VMT group actually increased its rush hour mileage in response to the pricing system. It appears that this group was grouping more of its travel around the rush hour trips since all mileage changes other than rush hour were reductions. The rush hour group reduced its a.m. mileage by a little more than the p.m. mileage, but the differences are small.

Table 5.1 Changes In Total Rush Hour Miles by A.M. and P.M. (Weekday)

\begin{tabular}{|l|l|r|r|r|r|}
\hline & & \multicolumn{4}{|c|}{ Paired Differences } \\
\hline Group & Time Period & Mean & t-ratio & $\begin{array}{r}\text { Sig. } \\
\text { (2-tailed) }\end{array}$ & $\begin{array}{r}\text { Percent } \\
\text { Change }\end{array}$ \\
\hline Control & A.M. & 4.359 & 1.378 & 0.202 & $25.14 \%$ \\
\hline Control & P.M. & 1.533 & 0.538 & 0.604 & $7.61 \%$ \\
\hline VMT & A.M. & 1.339 & 1.565 & 0.121 & $13.23 \%$ \\
\hline VMT & P.M. & 1.589 & 2.199 & 0.030 & $12.03 \%$ \\
\hline RH & A.M. & -2.777 & -3.132 & 0.002 & $-14.32 \%$ \\
\hline RH & P.M. & -2.724 & -3.021 & 0.003 & $-11.98 \%$ \\
\hline
\end{tabular}

However, Tables 5.2 and 5.3 show that there is substantial variation by day in the changes that occur. In particular, the RH group showed relatively small changes on Fridays and relatively large changes on Wednesdays and Thursdays. This is consistent with other reports of higher demand and lower price elasticity for rush hour travel on Fridays. For example, SR91 charges its highest congestion rates during the Friday afternoon peak. This would argue that for efficiency the toll may have to be varied by day of the week as well as by time. 
Table 5.2 Changes In A.M. Rush Hour Miles By Weekday

\begin{tabular}{|l|l|r|r|r|r|}
\hline & & \multicolumn{3}{|c|}{ Paired Differences } \\
\hline Group & Time Period & Mean & t-ratio & $\begin{array}{r}\text { Sig. } \\
\text { (2-tailed) }\end{array}$ & $\begin{array}{r}\text { Percent } \\
\text { Change }\end{array}$ \\
\hline Control & Monday 7:00-9:00 A.M. & 0.842 & 1.555 & 0.154 & $28.43 \%$ \\
\hline Control & Tuesday 7:00-9:00 A.M. & 1.643 & 1.818 & 0.102 & $49.27 \%$ \\
\hline Control & Wednesday 7:00-9:00A.M. & 0.661 & 1.031 & 0.330 & $17.75 \%$ \\
\hline Control & Thursday 7:00 9:00 A.M. & 0.197 & 0.260 & 0.801 & $5.08 \%$ \\
\hline Control & Friday 7:00-9:00 A.M. & 1.013 & 1.314 & 0.221 & $29.38 \%$ \\
\hline VMT & Monday 7:00-9:00 A.M. & 0.029 & 0.164 & 0.870 & $1.58 \%$ \\
\hline VMT & Tuesday 7:00-9:00 A.M. & 0.359 & 1.624 & 0.108 & $17.13 \%$ \\
\hline VMT & Wednesday 7:00-9:00 A.M. & 0.472 & 2.136 & 0.035 & $23.46 \%$ \\
\hline VMT & Thursday 7:00-9:00 A.M. & 0.214 & 0.997 & 0.321 & $10.11 \%$ \\
\hline VMT & Friday 7:00-9:00 A.M. & 0.263 & 1.459 & 0.148 & $12.91 \%$ \\
\hline RH & Monday 7:00-9:00 A.M. & -0.520 & -2.486 & 0.015 & $-15.54 \%$ \\
\hline RH & Tuesday 7:00-9:00 A.M. & -0.297 & -1.372 & 0.173 & $-7.95 \%$ \\
\hline RH & Wednesday 7:00-9:00 A.M. & -0.682 & -2.573 & 0.012 & $-15.78 \%$ \\
\hline RH & Thursday 7:00-9:00 A.M. & -1.002 & -4.578 & 0.00 & $-24.02 \%$ \\
\hline RH & Friday 7:00-9:00 A.M. & -0.278 & -1.226 & 0.223 & $-7.40 \%$ \\
\hline
\end{tabular}

Table 5.3 Changes In P.M. Rush Hour Miles By Weekday

\begin{tabular}{|l|l|r|r|r|r|}
\hline & & \multicolumn{3}{|c|}{ Paired Differences } \\
\hline Group & Time Period & Mean & t-ratio & $\begin{array}{r}\text { Sig. } \\
\text { (2-tailed) }\end{array}$ & Percent Change \\
\hline Control & Monday 4:00-6:00 P.M. & 0.892 & 1.215 & 0.255 & $27.24 \%$ \\
\hline Control & Tuesday 4:00-6:00 P.M. & 0.209 & 0.267 & 0.796 & $4.92 \%$ \\
\hline Control & Wednesday 4:00-6:00 P.M. & 0.371 & 0.453 & 0.661 & $8.22 \%$ \\
\hline Control & Thursday 4:00 6:00 P.M. & -0.025 & -0.039 & 0.969 & $-0.60 \%$ \\
\hline Control & Friday 4:00-6:00 P.M. & 0.086 & 0.187 & 0.856 & $2.17 \%$ \\
\hline VMT & Monday 4:00-6:00 P.M. & 0.665 & 3.723 & 0.000 & $28.40 \%$ \\
\hline VMT & Tuesday 4:00-6:00 P.M. & 0.279 & 1.290 & 0.200 & $10.73 \%$ \\
\hline VMT & Wednesday 4:00-6:00 P.M. & -0.021 & -0.092 & 0.927 & $-0.74 \%$ \\
\hline VMT & Thursday 4:00-6:00 P.M. & 0.101 & 0.499 & 0.619 & $3.56 \%$ \\
\hline VMT & Friday 4:00-6:00 P.M. & 0.564 & 2.587 & 0.011 & $21.59 \%$ \\
\hline RH & Monday 4:00-6:00 P.M. & -0.310 & -1.313 & 0.192 & $-7.39 \%$ \\
\hline RH & Tuesday 4:00-6:00 P.M. & -0.423 & -1.632 & 0.106 & $-9.53 \%$ \\
\hline RH & Wednesday 4:00-6:00 P.M. & -0.593 & -2.435 & 0.017 & $-12.84 \%$ \\
\hline RH & Thursday 4:00-6:00 P.M. & -0.982 & -4.323 & 0.000 & $-20.79 \%$ \\
\hline RH & Friday 4:00-6:00 P.M. & -0.416 & -1.511 & 0.134 & $-8.74 \%$ \\
\hline
\end{tabular}




\subsection{EFFECT OF TRANSIT SERVICE ON MILEAGE CHANGES}

\subsection{PERCEPTION AND ACTUAL DISTANCE}

As noted earlier, the survey question related to the distance in blocks to the nearest transit stop that could take participants where they want to go. While there is no way to adjust for the subjective element, it is possible to compare the actual distance to the nearest transit stop with the survey response. Four blocks represents approximately one-quarter mile for standard block sizes in Portland. The percentage of respondents indicating that transit was available within four blocks was compared with the percentage that had actual transit stops within one-quarter mile. The match was relatively close with about $10 \%$ fewer people reporting useful transit within four blocks relative to those with actual transit within one-quarter mile. Since the responses of less than four blocks and the actual distance of one-quarter mile did not necessarily correspond to the same household, this can best be viewed as the average difference between the two measures. It is not known how much is due to errors in estimating distance and how much is due to the perception that the transit available was not useful.

Next, a simple correlation was done between number of blocks reported and the actual distance to the nearest transit stop. Correlation between the reported blocks to transit and actual distance to nearest stop and to nearest frequent service stop were both about 0.3 . This indicates that distance and estimated blocks were somewhat consistent, but that there appears to be wide variation in the relationship between estimated and actual distance. In other words, people seem to estimate the distance fairly well on average, but individual estimates vary quite a lot, with overestimates by some being offset by underestimates by others. This reinforces the importance of doing the analysis with actual distance, since this is the information that would be available to analysts reviewing proposed pricing systems.

\subsection{TRANSIT ACCESS AND MILES DRIVEN}

There are two relevant methods to evaluate the relationship between transit service and miles driven from the experiment. The first is to examine the baseline miles driven and see whether various measures of transit distance or service affect the observed variation in baseline miles driven. The second is to use the same variables to see if they help explain differences in response to the mileage charges.

Table 6.1 shows descriptive statistics for the regression models using distance to transit derived from the survey. Table 6.2 shows regression results for rush hour miles and total miles. For example, the coefficient on transit access shows a statistically significant reduction of two peak period miles per weekday compared to an average of 6.8 miles per vehicle. On the other hand, good access to transit had a smaller and not statistically significant effect on the total number of miles driven. Of course, this result is subject to the concern that people who want to take transit 
choose to live near it, so this analysis shows no causality. However, people had a fixed location at the time of the experiment, so the effect of transit proximity on changes in mileage would be directly attributable to the transit availability. This effect was found, but it was not quite statistically significant. Table 6.3 shows that people who reported good access to transit showed a reduction of almost three-quarters of a mile per weekday in rush hour driving with a t-ratio of 1.8 as compared to people who did not report good transit access. There was also a reduction of about 1.5 miles per day in total driving, but this was not statistically significant.

Table 6.1 Descriptive Statistics for the Full Sample- Self-Reported Transit Access

\begin{tabular}{|l|r|r|r|}
\hline Variable & $\mathbf{N}$ & Mean & Std. Deviation \\
\hline Avg. Peak Miles/Weekday & 195 & 6.780 & 5.101 \\
\hline Avg. Total OR Miles/Day & 195 & 27.286 & 16.463 \\
\hline Avg. Total Miles/Day & 195 & 30.843 & 19.508 \\
\hline Difference in Peak Miles/Weekday & 195 & -0.160 & 2.756 \\
\hline Difference in Total OR Miles/Day & 195 & -3.176 & 7.817 \\
\hline Difference in Total Miles/Day & 195 & -3.984 & 9.521 \\
\hline Number of Vehicles in HH & 195 & 1.518 & 0.612 \\
\hline Number of Persons in HH & 195 & 1.759 & 0.731 \\
\hline Gender Dummy (Male) & 195 & 0.462 & 0.500 \\
\hline HH Income \$40K+ Dummy & 195 & 0.697 & 0.461 \\
\hline At Least 1 Person in HH Emp. FT Dummy & 195 & 0.667 & 0.473 \\
\hline Always Drive, Even if Transit Available Dummy & 195 & 0.405 & 0.492 \\
\hline Commuting w/o Car is Hassle Dummy & 195 & 0.697 & 0.461 \\
\hline Need Car b/c Sched. Changes Often Dummy & 195 & 0.241 & 0.429 \\
\hline Transit Access LT 4 Blocks Dummy & 195 & 0.631 & 0.484 \\
\hline Children Under 16 in HH Dummy & 195 & 0.277 & 0.449 \\
\hline Speed More Imp't Than Cost Dummy & 195 & 0.544 & 0.499 \\
\hline Willingness to pay Tax/Toll Dummy & 195 & 0.518 & 0.501 \\
\hline Gas Price Affects Travel Choices Dummy & 195 & 0.708 & 0.456 \\
\hline
\end{tabular}


Table 6.2 Baseline Period Regressions- Rush Hour Miles Per Vehicle per Weekday and Total Miles per Vehicle per Day Self-Reported Transit Access

\begin{tabular}{|c|c|c|}
\hline Variable & Rush Hour & Total \\
\hline \multirow{2}{*}{ Number of Vehicles in $\mathrm{HH}$} & $-3.016^{* *}$ & $-8.123 * *$ \\
\hline & $(-4.699)$ & $(-2.979)$ \\
\hline \multirow{2}{*}{ Number of Persons in $\mathrm{HH}$} & $1.390 * *$ & 4.173 \\
\hline & $(2.719)$ & $(1.921)$ \\
\hline \multirow{2}{*}{ Gender Dummy (Male) } & -1.039 & 1.542 \\
\hline & $(-1.442)$ & $(0.503)$ \\
\hline \multirow{2}{*}{ HH Income $\$ 40 \mathrm{~K}+$ Dummy } & $2.535 * *$ & 2.297 \\
\hline & $(3.030)$ & $(0.646)$ \\
\hline \multirow{2}{*}{ At Least 1 Person in HH Emp. FT Dummy } & 0.712 & 0.027 \\
\hline & $(0.915)$ & $(0.008)$ \\
\hline \multirow{2}{*}{ Always Drive, Even if Transit Available Dummy } & 0.421 & 0.061 \\
\hline & $(0.586)$ & $(0.020)$ \\
\hline \multirow{2}{*}{ Commuting w/o Car is Hassle Dummy } & $2.326^{* *}$ & 1.240 \\
\hline & $(3.031)$ & $(0.380)$ \\
\hline \multirow{2}{*}{ Need Car b/c Sched. Changes Often Dummy } & 0.423 & $6.754 *$ \\
\hline & $(0.528)$ & $(1.982)$ \\
\hline \multirow{2}{*}{ Transit Access LT 4 Blocks Dummy } & $-2.097 * *$ & -1.442 \\
\hline & $(-2.978)$ & $(-0.482)$ \\
\hline \multirow{2}{*}{ Children Under 16 in HH Dummy } & $1.900^{*}$ & 5.459 \\
\hline & $(2.364)$ & $(1.598)$ \\
\hline \multirow{2}{*}{ Speed More Imp't Than Cost Dummy } & 0.611 & 3.684 \\
\hline & $(0.865)$ & $(1.228)$ \\
\hline \multirow{2}{*}{ WTP Tax/Toll Dummy } & 0.599 & 1.138 \\
\hline & $(0.873)$ & $(0.390)$ \\
\hline \multirow{2}{*}{ Gas Price Affects Travel Choices Dummy } & 1.19 & 0.945 \\
\hline & $(1.593)$ & $(0.298)$ \\
\hline \multirow{2}{*}{ Constant } & $4.567^{* *}$ & $27.121^{* *}$ \\
\hline & (3.104) & $(4.338)$ \\
\hline$\overline{A d j .} R^{2}$ & 0.231 & 0.051 \\
\hline $\mathrm{N}$ & 195 & 195 \\
\hline
\end{tabular}

** Significant at the $99 \%$ level of confidence

* Significant at the $95 \%$ level of confidence

Table 6.3 Change Regressions- Rush Hour Miles per Vehicle Per Weekday and Total Miles per Vehicle Per Day Self-Reported Transit Access

\begin{tabular}{|l|c|c|}
\hline Variable & Rush Hour & Total \\
\hline \multirow{2}{*}{ Number of Vehicles in HH } & 0.650 & 1.449 \\
\cline { 2 - 3 } & $(1.703)$ & $(1.07)$ \\
\hline \multirow{2}{*}{ Number of Persons in HH } & -0.445 & $-2.826^{* *}$ \\
\cline { 2 - 3 } & $(-1.491)$ & $(-2.667)$ \\
\hline \multirow{2}{*}{ Gender Dummy (Male) } & 0.116 & $2.982^{*}$ \\
\hline \multirow{2}{*}{ Rush Hour Group Dummy } & $(0.275)$ & -2.189 \\
\hline \multirow{2}{*}{ Control Group Dummy } & $-1.507^{* *}$ & $(-1.509)$ \\
\hline HH Income \$40K+ Dummy & $(-3.687)$ & 1.444 \\
\cline { 2 - 3 } & 0.268 & $(0.447)$ \\
\hline
\end{tabular}




\begin{tabular}{|l|c|c|}
\hline & $(-0.928)$ & $(-0.855)$ \\
\hline \multirow{2}{*}{ At Least 1 Person in HH Emp. FT Dummy } & 0.081 & 1.132 \\
\hline \multirow{2}{*}{ Always Drive, Even if Transit Available Dummy } & $(0.176)$ & $(0.693)$ \\
\cline { 2 - 3 } Commuting w/o Car is Hassle Dummy & -0.065 & $(2.971)$ \\
\cline { 2 - 3 } & $(-0.155)$ & -2.408 \\
\hline \multirow{2}{*}{ Need Car b/c Sched. Changes Often Dummy } & -0.621 & $(-1.511)$ \\
\hline \multirow{2}{*}{ Transit Access LT 4 Blocks Dummy } & $-1.383)$ & $(.158$ \\
\hline \multirow{2}{*}{ Children Under 16 in HH Dummy } & -0.662 & $\mathbf{- 1 . 4 7 8}$ \\
\hline \multirow{2}{*}{ Speed More Imp't Than Cost Dummy } & $\mathbf{- 0 . 7 4 2}$ & $\mathbf{( - 1 . 0 1 5 )}$ \\
\hline \multirow{2}{*}{ WTP Tax/Toll Dummy } & $\mathbf{( - 1 . 8 0 6 )}$ & 2.400 \\
\hline \multirow{2}{*}{ Gas Price Affects Travel Choices Dummy } & 0.754 & $(1.442)$ \\
\hline \multirow{2}{*}{ Constant } & $(1.607)$ & $(0.023$ \\
\hline & 0.054 & 0.664 \\
\hline & $(0.131)$ & $(0.466)$ \\
\hline Adj. ${ }^{2}$ & 0.181 & -0.179 \\
\hline $\mathrm{N}$ & $(0.451)$ & $(-0.114)$ \\
\cline { 2 - 3 } & -0.336 & -2.171 \\
\cline { 2 - 3 } & $(-0.761)$ & $(-0.705)$ \\
\hline
\end{tabular}

** Significant at the $99 \%$ level of confidence

* Significant at the $95 \%$ level of confidence

This data is relatively unique in that it allows us to examine the relationship between transit access and either miles driven or changes in miles driven in response to the mileage charge. Most transit studies focus on mode choice or on the amount of transit use. While mode choice and transit use information is useful, it does not provide direct information on the effect of transit on miles driven. For example, increased transit use might reflect more trips rather than a reduction in driving.

Previous research has found that use of transit is also affected by the amount of service available (Peng et al. 1997). This was addressed by generating various measures of service available within various distances of the residence. The measures of quantity used were the number of routes available within a specified distance and the number of frequent service routes available. Regressions using these measures of service available within various distances found small and not statistically significant effects for more service on mileage driven or changes in mileage driven. Therefore, these results are not reported.

Table 6.4 shows descriptive statistics for the regression models using distance to transit variables derived from household locations using a GIS. Table 6.5 shows the effect of distance to transit service on peak miles driven in the baseline period. The surprising finding is that the further one is from transit the less peak period driving is done; but this coefficient is small and not statistically significant. Perhaps even more surprising is that Table 6.5 also shows that distance to transit does affect total driving in the baseline period, with each additional mile to a transit stop leading to a statistically significant increase of 1.27 miles in average daily mileage. All of the regressions reported here were also run using distance to frequent service as the variable. 
The results were consistent with the use of simple distance to transit and distance alone appeared to be the better measure, so these are the results reported.

Table 6.4 Descriptive Statistics for the Full Sample- GIS-Based Transit Access

\begin{tabular}{|c|c|c|c|}
\hline Variable & $\mathbf{N}$ & Mean & $\begin{array}{r}\text { Std. } \\
\text { Deviation }\end{array}$ \\
\hline Avg. Peak Miles/Weekday & 177 & 6.710 & 5.271 \\
\hline Avg. Total OR Miles/Day & 177 & 26.291 & 13.627 \\
\hline Avg. Total Miles/Day & 177 & 29.359 & 14.855 \\
\hline Difference in Peak Miles/Weekday & 177 & -0.239 & 2.754 \\
\hline Difference in Total OR Miles/Day & 177 & -3.405 & 7.766 \\
\hline Difference in Total Miles/Day & 177 & -3.788 & 9.217 \\
\hline Number of Vehicles in $\mathrm{HH}$ & 177 & 1.514 & 0.623 \\
\hline Number of Persons in $\mathrm{HH}$ & 177 & 1.763 & 0.746 \\
\hline Gender Dummy (Male) & 177 & 0.446 & 0.499 \\
\hline HH Income $\$ 40 \mathrm{~K}+$ Dummy & 177 & 0.695 & 0.462 \\
\hline At Least 1 Person in HH Emp. FT Dummy & 177 & 0.667 & 0.473 \\
\hline Always Drive, Even if Transit Available Dummy & 177 & 0.435 & 0.497 \\
\hline Commuting w/o Car is Hassle Dummy & 177 & 0.706 & 0.457 \\
\hline Need Car b/c Sched. Changes Often Dummy & 177 & 0.237 & 0.427 \\
\hline Speed More Imp't Than Cost Dummy & 177 & 0.537 & 0.500 \\
\hline WTP Tax/Toll Dummy & 177 & 0.508 & 0.501 \\
\hline Gas Price Affects Travel Choices Dummy & 177 & 0.689 & 0.464 \\
\hline Children Under 16 in HH Dummy & 177 & 0.271 & 0.446 \\
\hline Distance to Closest Transit Stop (Miles) & 177 & 0.440 & 1.959 \\
\hline
\end{tabular}

Table 6.5 Baseline Period Effect of Distance to Transit on Miles Driven

\begin{tabular}{|l|l|l|}
\hline \multirow{2}{*}{ Variable } & $\begin{array}{l}\text { Peak Miles } \\
\text { Driven }\end{array}$ & $\begin{array}{l}\text { Total Miles } \\
\text { Driven }\end{array}$ \\
\hline \multirow{2}{*}{ Number of Vehicles in HH } & $-2.717^{* *}$ & $-7.156^{* *}$ \\
\cline { 2 - 3 } & $(-3.963)$ & $(-3.544)$ \\
\hline \multirow{2}{*}{ Number of Persons in HH } & $1.476^{* *}$ & $6.006^{* *}$ \\
\cline { 2 - 3 } & $(2.729)$ & $(3.773)$ \\
\hline \multirow{2}{*}{ Gender Dummy (Male) } & -1.423 & -2.068 \\
\cline { 2 - 3 } & $(-1.762)$ & $(-0.869)$ \\
\hline \multirow{2}{*}{ Rush Hour Group Dummy } & $2.408^{* *}$ & $5.280^{*}$ \\
\cline { 2 - 3 } & $(3.130)$ & $(2.331)$ \\
\hline \multirow{2}{*}{ Control Group Dummy } & 1.476 & -0.210 \\
\cline { 2 - 3 } & $(0.830)$ & $(-0.040)$ \\
\hline \multirow{2}{*}{ HH Income \$40K+ Dummy } & $2.805^{* *}$ & 5.229 \\
\cline { 2 - 3 } & $(3.038)$ & $(1.924)$ \\
\hline \multirow{2}{*}{ At Least 1 Person in HH Emp. FT Dummy } & -0.061 & 0.007 \\
\cline { 2 - 3 } & $(-0.072)$ & $(0.003)$ \\
\hline \multirow{2}{*}{ Always Drive, Even if Transit Available Dummy } & -0.217 & -2.959 \\
\cline { 2 - 3 } & $(-0.278)$ & $(-1.290)$ \\
\hline \multirow{2}{*}{ Commuting w/o Car is Hassle Dummy } & $2.220^{* *}$ & 4.328 \\
\cline { 2 - 3 } & $(2.599)$ & $(1.721)$ \\
\hline \multirow{2}{*}{ Need Car b/c Sched. Changes Often Dummy } & 1.675 & 3.814 \\
\cline { 2 - 3 } & $(1.925)$ & $(1.488)$ \\
\hline
\end{tabular}




\begin{tabular}{|l|l|l|}
\hline \multirow{2}{*}{ Distance to Closest Transit Stop (Miles) } & $\mathbf{- 0 . 1 9 5}$ & $\mathbf{1 . 2 7 1}^{*}$ \\
\cline { 2 - 3 } & $\mathbf{( - 0 . 9 9 6 )}$ & $\mathbf{( 2 . 2 0 9}$ \\
\hline \multirow{2}{*}{ Children Under 16 in HH Dummy } & 1.226 & 1.950 \\
\cline { 2 - 3 } & $(1.386)$ & $(0.749)$ \\
\hline \multirow{2}{*}{ Speed More Imp't Than Cost Dummy } & 0.501 & 1.209 \\
\cline { 2 - 3 } & $(0.655)$ & $(0.536)$ \\
\hline \multirow{2}{*}{ WTP Tax/Toll Dummy } & -0.105 & 0.207 \\
\cline { 2 - 3 } & $(-0.143)$ & $(0.096)$ \\
\hline \multirow{2}{*}{ Gas Price Affects Travel Choices Dummy } & 0.909 & -1.783 \\
\cline { 2 - 3 } & $(1.135)$ & $(-0.756)$ \\
\hline \multirow{2}{*}{ Constant } & 2.781 & $21.106^{* *}$ \\
\cline { 2 - 3 } & $(1.873)$ & $(4.829)$ \\
\hline & & \\
\hline Adj. $\mathrm{R}^{2}$ & 0.247 & 0.178 \\
\hline $\mathrm{N}$ & 177 & 177 \\
\hline
\end{tabular}

** Significant at the $99 \%$ level of confidence

* Significant at the $95 \%$ level of confidence

Table 6.6 shows that each additional mile to transit results in a statistically significant increase of 0.23 miles in peak period usage in response to the mileage fees, holding everything else constant. Since there is a fairly substantial reduction in peak miles in response to the fees, it means that people with close transit access reduce their mileage by more than people without close transit access. Also, Table 6.6 shows that for each additional mile to transit, daily mileage increases by 0.3 miles, but this result is not statistically significant.

Table 6.6 Effect of Distance to Transit on Changes in Miles

\begin{tabular}{|l|l|l|}
\hline \multirow{2}{*}{ Variable } & $\begin{array}{l}\text { Change in } \\
\text { Peak Miles } \\
\text { Driven }\end{array}$ & $\begin{array}{l}\text { Change in } \\
\text { Total Miles } \\
\text { Driven }\end{array}$ \\
\hline \multirow{2}{*}{ Number of Vehicles in HH } & 0.578 & 1.544 \\
\cline { 2 - 3 } & $(1.514)$ & $(1.147)$ \\
\hline \multirow{2}{*}{ Number of Persons in HH } & -0.404 & $-2.944 * *$ \\
\cline { 2 - 3 } Gender Dummy (Male) & $(-1.343)$ & $(-2.772)$ \\
\hline \multirow{2}{*}{ Rush Hour Group Dummy } & 0.217 & 2.300 \\
\cline { 2 - 3 } & $(0.484)$ & $(1.450)$ \\
\hline \multirow{2}{*}{ Control Group Dummy } & $-1.570 * *$ & -2.611 \\
\cline { 2 - 3 } & $(-3.667)$ & $(-1.728)$ \\
\hline \multirow{2}{*}{ HH Income \$40K+ Dummy } & 0.179 & -0.832 \\
\cline { 2 - 3 } & $(0.181)$ & $(-0.238)$ \\
\hline \multirow{2}{*}{ At Least 1 Person in HH Emp. FT Dummy } & -0.544 & -0.609 \\
\cline { 2 - 3 } & $(-1.059)$ & $(-0.336)$ \\
\hline \multirow{2}{*}{ Always Drive, Even if Transit Available Dummy } & -0.061 & 0.388 \\
\cline { 2 - 3 } & $(-0.128)$ & $(0.232)$ \\
\hline Commuting w/o Car is Hassle Dummy & 0.058 & $4.338^{* *}$ \\
\cline { 2 - 3 } & $(0.135)$ & $(2.835)$ \\
\hline
\end{tabular}




\begin{tabular}{|l|l|l|}
\hline & $(-2.060)$ & $(-1.676)$ \\
\hline \multirow{2}{*}{ Need Car b/c Sched. Changes Often Dummy } & -0.816 & 0.249 \\
\cline { 2 - 3 } & $(-1.684)$ & $(0.146)$ \\
\hline \multirow{2}{*}{ Distance to Closest Transit Stop (Miles) } & $\mathbf{0 . 2 3 4}$ & $\mathbf{0 . 3 1 3}$ \\
\cline { 2 - 3 } & $\mathbf{( 2 . 1 5 0 )}$ & $\mathbf{( 0 . 8 1 5 )}$ \\
\hline \multirow{2}{*}{ Children Under 16 in HH Dummy } & 0.763 & 2.819 \\
\cline { 2 - 3 } & $(1.549)$ & $(1.623)$ \\
\hline \multirow{2}{*}{ Speed More Imp't Than Cost Dummy } & -0.079 & 1.330 \\
\cline { 2 - 3 } & $(-0.185)$ & $(0.884)$ \\
\hline \multirow{2}{*}{ WTP Tax/Toll Dummy } & 0.311 & 0.016 \\
\cline { 2 - 3 } & $(0.760)$ & $(0.011)$ \\
\hline \multirow{2}{*}{ Gas Price Affects Travel Choices Dummy } & -0.262 & 0.102 \\
\cline { 2 - 3 } & $(-0.589)$ & $(0.065)$ \\
\hline \multirow{2}{*}{ Constant } & 1.272 & -2.177 \\
\cline { 2 - 3 } & $(1.540)$ & $(-0.747)$ \\
\hline Adj. $\mathrm{R}^{2}$ & & \\
\hline $\mathrm{N}$ & 0.146 & 0.050 \\
\hline
\end{tabular}

** Significant at the $99 \%$ level of confidence

* Significant at the $95 \%$ level of confidence

Both the peak period prices and the off-peak prices were different for the VMT and RH groups, so this might create different incentives for use of transit. Regressions were run on the subsamples to see if there were different responses in the two cases. Unfortunately, the small sample sizes yielded few statistically significant results. There did appear to be a larger effect of access to transit for the rush hour response of the congestion pricing group, but the low statistical significance of the coefficient cautions against reliance on the specific magnitude.

\subsection{EFFECT OF TRANSIT ACCESS}

In the Oregon mileage experiment, access to transit had an effect on how much people changed their mileage in response to prices. The effect is largely associated with distance to a transit stop rather than with measures of the level of service. Obviously, this was a very limited experiment and the findings should be applied to other situations with great care. However, these findings imply that road pricing is likely to be more effective in reducing rush hour mileage in areas with good access to transit. The effect is small but statistically significant. Less clear is whether there would be any effect of access to transit on total mileage. 


\subsection{EFFECT OF HOUSEHOLD INCOME ON MILEAGE AND CHANGES IN MILEAGE}

In the initial analysis of the data, a set of demographic variables was included to examine the effect of demographic differences in baseline mileage and changes in mileage due to the mileage fees. However, the data set has additional information that was not analyzed in the earlier review. A number of refinements in the demographic data were examined for their effect on either baseline mileage or changes in mileage. Most of the refinements showed little additional information as compared to the initial results; however, the income data did allow for more refinement of the results. One interesting result in the early review was that people with household income above $\$ 40,000$ per year drove more than those with lower incomes, but the higher income groups reduced mileage a little more in the experiment. The latter effect was small and not statistically significant, but it runs counter to the expectation that higher income households would be less affected by the pricing and so would reduce their mileage by less. The only income data reported was for the categories "under $\$ 20,000$," "over $\$ 20,000$ and less than $\$ 40,000$," "over $\$ 40,000$ and less than $\$ 60,000$," and "over $\$ 60,000$." The dummy variable used in the initial analysis was simply for household income above $\$ 40,000$. To refine the estimates of the effect of income, all of the income groupings were used. The "over $\$ 60,000$ " group was chosen as the omitted one since the "under $\$ 20,000$ " category had a small sample size.

The results of including the more refined income categories are reported in Tables 7.1 and 7.2. Table 7.1 confirms the finding that higher income households did have greater mileage per vehicle, but there are also substantial differences between the "under $\$ 20,000$ " and the "between $\$ 20,000$ and \$40,000" income levels, with the lowest income group showing much lower, although often not statistically significant, mileage levels than the other groups. Table 7.2 shows that the income group that had the smallest reduction in total mileage due to the mileage charge was the $\$ 20,000$ to $\$ 40,000$ group. While this result alone does not show much, it raises the important issue that the impact on different income groups will vary. One possible explanation for this result is that the higher income households have more flexibility to change behavior in response to the charges than the middle income households, and the low income households have more incentive due to financial constraints. In any case, it implies that the financial impact is not monotonic with respect to income.

Table 7.1 Baseline Period- Effect of Income On Rush Hour Miles per Vehicle per Weekday, Total Oregon Miles per Vehicle per Day, and Total Miles per Vehicle per Day

\begin{tabular}{|l|c|c|c|}
\hline \multirow{2}{*}{ Variables } & & & \\
& & & \\
& & \\
Number of Vehicles in HH & Oregon Hour & Total Miles \\
\hline \multirow{2}{*}{ Number of Persons in HH } & $-2.684^{* *}$ & $-7.867^{* *}$ & $-8.146^{* *}$ \\
\cline { 2 - 4 } & $(-4.036)$ & $(-3.362)$ & $(-2.894)$ \\
\hline Gender Dummy (Male) & $1.536^{* *}$ & $5.106^{* *}$ & $4.497^{*}$ \\
\cline { 2 - 4 } & $(2.948)$ & $(2.784)$ & $(2.039)$ \\
\hline
\end{tabular}




\begin{tabular}{|c|c|c|c|}
\hline & $(-1.760)$ & $(-0.028)$ & $(0.147)$ \\
\hline \multirow{2}{*}{ At Least 1 Person in HH Emp. FT Dummy } & 0.449 & -0.528 & -1.028 \\
\hline & $(0.554)$ & $(-0.185)$ & $(-0.299)$ \\
\hline \multirow{2}{*}{ Always Drive, Even if Transit Available Dummy } & 0.461 & -0.589 & 0.04 \\
\hline & (0.632) & $(-0.229)$ & $(0.013)$ \\
\hline \multirow{2}{*}{ Commuting w/o Car is Hassle Dummy } & $2.215 * *$ & 2.546 & 1.366 \\
\hline & $(2.851)$ & $(0.931)$ & $(0.416)$ \\
\hline \multirow{2}{*}{ Need Car b/c Sched. Changes Often Dummy } & 0.59 & $5.987 *$ & $6.938^{*}$ \\
\hline & $(0.721)$ & $(2.079)$ & $(2.003)$ \\
\hline \multirow{2}{*}{ Transit Access LT 4 Blocks Dummy } & $-2.105 * *$ & -0.447 & -1.776 \\
\hline & $(-2.907)$ & $(-0.175)$ & $(-0.579)$ \\
\hline \multirow{2}{*}{ Children Under 16 in HH Dummy } & $1.878^{*}$ & 4.367 & 4.937 \\
\hline & $(2.268)$ & $(1.498)$ & $(1.408)$ \\
\hline \multirow{2}{*}{ Speed More Imp't Than Cost Dummy } & 0.768 & 2.828 & 3.903 \\
\hline & $(1.065)$ & (1.114) & $(1.279)$ \\
\hline \multirow{2}{*}{ WTP Tax/Toll Dummy } & 0.556 & 1.472 & 1.428 \\
\hline & $(0.782)$ & $(0.589)$ & $(0.475)$ \\
\hline \multirow{2}{*}{ Gas Price Affects Travel Choices Dummy } & 1.08 & 0.75 & 0.538 \\
\hline & $(1.404)$ & $(0.277)$ & $(0.165)$ \\
\hline \multirow{2}{*}{ HH Income Dummy Less Than $\$ 20,000$} & -2.938 & -5.816 & -7.568 \\
\hline & $(-1.852)$ & $(-1.042)$ & $(-1.127)$ \\
\hline \multirow{2}{*}{ HH Income Dummy Between \$20,000-\$40,000 } & -1.537 & -1.24 & -1.353 \\
\hline & $(-1.505)$ & $(-0.345)$ & $(-0.313)$ \\
\hline \multirow{2}{*}{ HH Income Dummy Between $\$ 40,000-\$ 60,000$} & 1.013 & -0.876 & 0.182 \\
\hline & (1.232) & $(-0.302)$ & $(0.052)$ \\
\hline \multirow{2}{*}{ Constant } & $6.024 * *$ & $24.619 * *$ & $30.080 * *$ \\
\hline & $(3.375)$ & $(3.92)$ & $(3.982)$ \\
\hline Adj. $R^{2}$ & 0.224 & 0.071 & 0.043 \\
\hline $\mathrm{N}$ & 191 & 191 & 191 \\
\hline
\end{tabular}

** Significant at the $99 \%$ level of confidence

* Significant at the $95 \%$ level of confidence

Table 7.2 Effect of Income On Change in Rush Hour Miles per Vehicle per Weekday, Change in Total Oregon Miles per Vehicle per Day, and Change in Total Miles per Vehicle per Day

\begin{tabular}{|l|c|c|c|}
\hline \multirow{2}{*}{ Variables } & & & \\
\hline \multirow{2}{*}{ Number of Vehicles in HH } & Rush Hour & Oregon & Total Miles \\
\hline \multirow{2}{*}{ Number of Persons in HH } & 0.416 & 0.944 & 1.579 \\
\cline { 2 - 4 } & $(1.118)$ & $(0.853)$ & $(1.129)$ \\
\hline \multirow{2}{*}{ Gender Dummy (Male) } & -0.378 & $-3.612^{* *}$ & $-2.996^{* *}$ \\
\hline \multirow{2}{*}{ Rush Hour Group Dummy } & -0.097 & $2.950^{*}$ & $3.177^{*}$ \\
\cline { 2 - 4 } & $(-0.236)$ & $(2.421)$ & $(2.062)$ \\
\hline \multirow{2}{*}{ Control Group Dummy } & $-1.602^{* *}$ & -2.069 & -2.142 \\
\hline \multirow{2}{*}{ At Least 1 Person in HH Emp. FT Dummy } & $(-4.102)$ & $(-1.783)$ & $(-1.460)$ \\
\hline \multirow{2}{*}{ Always Drive, Even if Transit Available Dummy } & 0.3 & 0.603 & 1.023 \\
\cline { 2 - 4 } & $(0.33)$ & $(0.222)$ & $(0.299)$ \\
\cline { 2 - 4 } & $(-0.147)$ & $(0.516)$ & $(0.696)$ \\
\cline { 2 - 4 } & -0.159 & $3.484^{* *}$ & $4.260^{* *}$ \\
\hline
\end{tabular}




\begin{tabular}{|c|c|c|c|}
\hline \multirow{2}{*}{ Commuting w/o Car is Hassle Dummy } & -0.62 & -2.037 & -2.031 \\
\hline & $(-1.446)$ & $(-1.598)$ & $(-1.260)$ \\
\hline \multirow{2}{*}{ Need Car b/c Sched. Changes Often Dummy } & -0.672 & -0.839 & 0.479 \\
\hline & $(-1.491)$ & $(-0.626)$ & $(0.282)$ \\
\hline \multirow{2}{*}{ Transit Access LT 4 Blocks Dummy } & $-0.923 *$ & $-2.583 *$ & -1.927 \\
\hline & $(-2.313)$ & $(-2.176)$ & $(-1.285)$ \\
\hline \multirow{2}{*}{ Children Under 16 in HH Dummy } & 0.693 & 1.823 & 2.872 \\
\hline & $(1.515)$ & $(1.342)$ & $(1.672)$ \\
\hline \multirow{2}{*}{ Speed More Imp't Than Cost Dummy } & -0.037 & 1.054 & 1.313 \\
\hline & $(-0.093)$ & $(0.889)$ & $(0.875)$ \\
\hline \multirow{2}{*}{ WTP Tax/Toll Dummy } & 0.451 & 0.188 & 0.965 \\
\hline & $(1.15)$ & $(0.162)$ & $(0.655)$ \\
\hline \multirow{2}{*}{ Gas Price Affects Travel Choices Dummy } & -0.138 & 0.018 & 0.104 \\
\hline & $(-0.321)$ & $(0.014)$ & $(0.064)$ \\
\hline \multirow{2}{*}{ HH Income Dummy Less Than $\$ 20,000$} & -0.285 & 0.441 & 1.043 \\
\hline & $(-0.326)$ & $(0.169)$ & $(0.317)$ \\
\hline \multirow{2}{*}{ HH Income Dummy Between $\$ 20,000-\$ 40,000$} & 0.281 & 3.075* & 2.914 \\
\hline & $(0.499)$ & $(1.836)$ & (1.376) \\
\hline \multirow{2}{*}{ HH Income Dummy Between $\$ 40,000-\$ 60,000$} & -0.675 & 0.309 & 0.302 \\
\hline & $(-1.491)$ & $(0.229)$ & $(0.178)$ \\
\hline \multirow{2}{*}{ Constant } & 1.791 & 0.713 & -4.439 \\
\hline & $(1.802)$ & $(0.241)$ & $(-1.188)$ \\
\hline Adj. $R^{2}$ & 0.144 & 0.108 & 0.05 \\
\hline $\mathrm{N}$ & 191 & 191 & 191 \\
\hline
\end{tabular}

** Significant at the $99 \%$ level of confidence

* Significant at the $95 \%$ level of confidence 


\subsection{COMPARISON WITH OTHER EXPERIMENTS}

There have been a variety of other experiments that have imposed some form of mileage charge on participants. Since the experiments varied substantially, it is not possible to make simple comparisons among them. However, each experiment evaluated certain items that are important in determining the overall impact of the mileage charges.

The Puget Sound Regional Council (2008) reports on an experiment that imposed congestion pricing on vehicles in the Puget Sound. This experiment equipped vehicles with a GPS-based system that tracked all vehicle usage and reported this to a central database. Vehicles were assessed mileage charges that varied by time of day and road class. Several of the key findings are very consistent with the findings from this experiment. Vehicles subject to tolls showed a $13 \%$ reduction in miles on tolled roads and a $12 \%$ reduction in miles per week (p. 12). While the specific amount and imposition of the tolls differed, the general magnitude was similar to the charges levied in this study, and the mileage reductions were also quite similar.

Since this was also a short-term experiment, all of the concerns regarding behavior while in an experiment and the lack of long-term options for adjusting apply as well. In addition, participants in this experiment also did not see any actual reduction in congestion, as would be expected if this behavior applied to the entire population, so the result is purely a price effect and would overstate the impact of actual congestion pricing since the improved travel time would partially offset the disincentive created by the pricing system. Nevertheless, the rough similarity between the results of the two experiments provides additional confidence that the observed results are reasonably representative of the short-run response to congestion pricing.

Other reported findings from the Puget Sound experiment are also consistent with the findings reported here. For example, they also found that the demand response was less pronounced with higher incomes and more pronounced with better transit options available.

The Puget Sound study looked at congestion pricing but did not include a flat mileage charge as part of the experiment. In contrast, a study in Minneapolis looked at converting fixed costs of automobile usage into a flat mileage charge (Abou-Zeid et al. 2008). This experiment included both flat mileage charges and differential charges between the peak and off-peak. The flat fee group was subdivided, with some paying 5 cents, 10 cents, 15 cents or 20 cents per mile. The peak period group could pay a fee as high as 25 cents per mile. Hence, this experiment was in many ways similar to the Oregon experiment. However, the small sample size and complex pricing system resulted in a lack of statistically significant findings. The nature of the experiment was somewhat different since the Oregon experiment was based on replacing a recurring charge (the state fuel tax) with an approximately equivalent mileage charge. Nevertheless, drivers in each experiment were faced with a mileage charge that was offset by reductions in other charges. While the findings were not statistically significant, they were consistent in direction with the findings in the Oregon study. 


\subsection{CONCLUSIONS}

The results reported here offer more of an introduction into the analysis of the effect of mileage fees on behavior than any definitive conclusions. As noted in the report on the initial analysis of this data, the respondents are by no means a random sample of the population and various characteristics of the experiment may have biased some of the results. Nevertheless, the findings are informative with respect to the likely impact of prices on behavior and some of the factors that may influence the behavioral response. The most important conclusion is that congestion pricing caused a reduction in peak period driving. In addition, the shift from fuel taxes to VMT fees caused people in the experiment to change their behavior. However, the analysis here offers some additional insight into factors that are likely to affect these responses.

The experiment was designed to allow evaluation of how participants' attitudes affected their response to the pricing systems. Attitudes do appear to have some relevance to these responses, but the changes in response to one key question across surveys raises concerns about how reliable attitude information is and whether it provides much information about likely responses to pricing.

There has been concern that replacing the gas tax with a mileage fee would encourage more driving with less fuel efficient vehicles while discouraging driving with more fuel efficient vehicles since the cost per mile to the less fuel efficient vehicles would decline while the cost per mile to the more fuel efficient vehicles would increase. There was a very small but not statistically significant effect of EPA mileage ratings on the changes in behavior in response to the shift from the fuel tax to a flat mileage fee. This is a reasonable result since the change in cost per mile was relatively small compared with other costs of driving. In addition, this only reflects the changes in use of a given vehicle and does not reflect the possibility that a permanent change might affect the probability that a person would choose a more fuel efficient or less fuel efficient vehicle. However, given the very small observed effect, this would not seem to be a significant issue.

The ability of congestion pricing to help manage the use of roads is based on the expectation that demand to use the roads varies by time of day. Effective congestion pricing would be easier to implement if the changes in demand were fairly consistent from day to day. Unfortunately, this does not seem to be the case. Analysis of the changes in rush hour driving by day of week and morning versus evening leads to the conclusion that the morning-evening responses are fairly similar but that there are substantial differences by day of the week.

Some of the other noteworthy findings from this report are that the availability of transit does affect how much people reduce their driving in response to prices. While the estimated coefficients should be treated with caution, they are among the first direct estimates of how the availability of transit service affects how people respond to mileage pricing. It also appears that household income affects how people respond to prices but that the relationship between income and changes in behavior is not a simple linear one. These findings may lead to more refined 
research on the relationship between road pricing and changes in behavior and better design of pricing systems. 


\subsection{REFERENCES}

M. Abou-Zeid, M. Ben-Akiva, K. Tierney, K. Buckeye, and J. Buxbaum, "Minnesota Pay-AsYou-Drive Pricing Experiment " Transportation Research Record, 2079, 8-14, 2008.

Kittelson and Associates, Inc. "A Guidebook for Developing a Transit Performance Measurement System." In TRCP Report 88, Transportation Research Board of the National Academies, Washington, D.C., $2003 a$.

Kittelson and Associates, Inc. "Transit Capacity and Quality of Service Manual- 2nd Edition." In TRCP Report 100, Transportation Research Board of the National Academies, Washington, D.C., 2003b.

B. S. McMullen and L. Zhang, "Techniques For Assessing The Socio-Economic Effects Of Vehicle Mileage Fees, OTREC-RR-08-1, 2008.

Z-R Peng, K. J. Dueker, J. Strathman, and J. Hopper. A Simultaneous Route-Level Transit Patronage Model: Demand, Supply, and Inter-route Relationships. Transportation, Vol. 24, No. 2, 1997, pp. 159-81.

Puget Sound Regional Council, “Traffic Choices Study - Summary Report”, 2008.

A. M. Rufolo and T. J. Kimpel. Responses to Oregon's Experiment in Road Pricing. Transportation Research Record, 2079, 1-7, 2008. 


\section{SO OTREC \\ AND EDUCATION CONSORTIUM}

P.O. Box 751

Portland, OR 97207

OTREC is dedicated to stimulating and conducting collaborative multi-disciplinary research on multi-modal surface transportation issues, educating a diverse array of current practitioners and future leaders in the transportation field, and encouraging implementation of relevant research results. 